Supporting Information

\title{
Reactivity of Functionalized Vinyl Monomers in Insertion
}

\section{Copolymerization}

\author{
Nicole Schuster, Thomas Rünzi and Stefan Mecking*
}

Chair of Chemical Materials Science, Department of Chemistry, University of Konstanz,

Universitätsstraße 10, D-78457 Konstanz, Germany 


\section{Table of Contents}

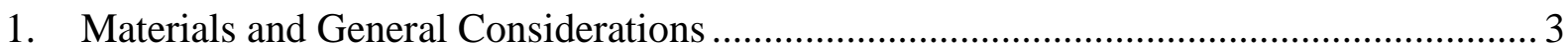

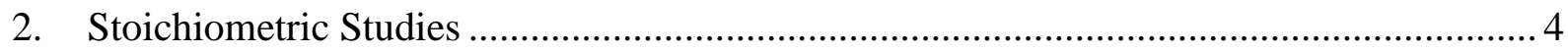

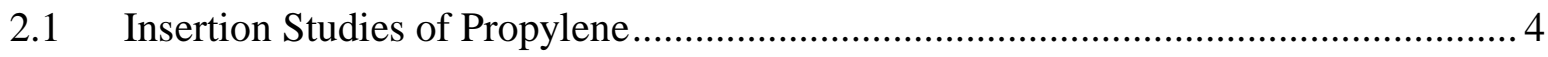

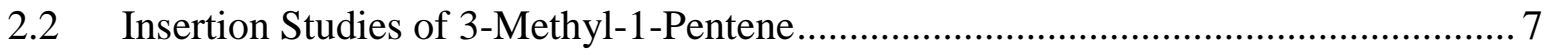

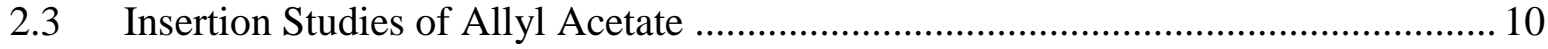

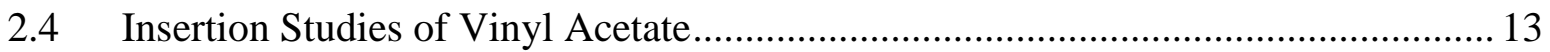

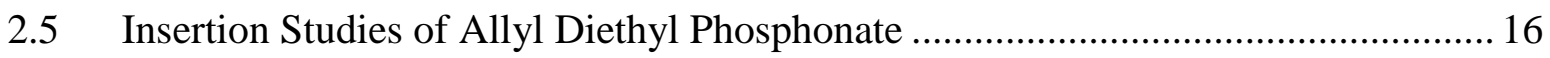

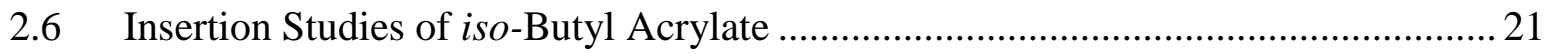

3. Pressure Reactor Polymerization Experiments ........................................................... 22

3.1 General Procedures for Co- and Terpolymerizations ......................................... 22

3.2 Copolymerization of Ethylene and Propylene ….................................................... 22

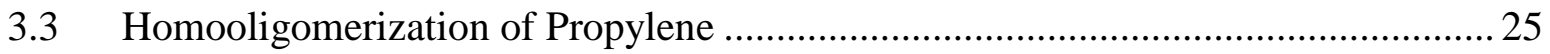

3.4 Terpolymerizations of Propylene, Ethylene and Polar Vinyl Monomers ................ 28

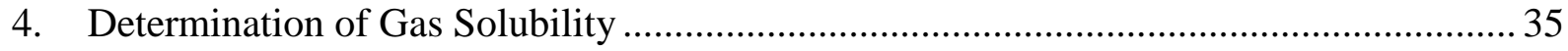

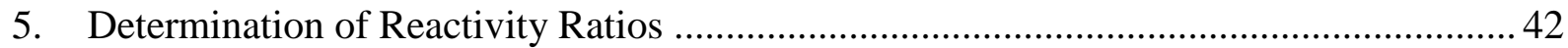

6. Determination of Reactivity Ratios $r_{A}$ for Selected Vinyl Monomers via Fineman-Ross 47

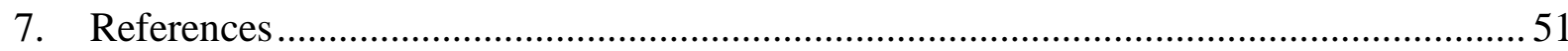




\section{Materials and General Considerations}

All polymerizations and manipulations of complexes or monomers were carried out under an inert gas atmosphere using standard glovebox or Schlenk techniques unless noted otherwise. Glassware was flame-dried under vacuum prior to use. Toluene was distilled from sodium. Ethylene (99.95\%) supplied by Praxair and propylene supplied by BASF were used as received. All monomers were purchased from either Sigma Aldrich, Acros Organics or ABCR. They were degassed with threeze-pump-thaw-cycles and stored under inert gas atmosphere and optionally with exclusion of light (acrylates and acrylic acid). Acrylic acid was dried over $\mathrm{MgSO}_{4}$, distilled and stored under inert gas atmosphere with added 3,5-di-tertbutyl-4-hydroxytoluene at $4{ }^{\circ} \mathrm{C}$. Allyl acetate was dried over $\mathrm{MgSO}_{4}$ and distilled. Ethyl vinyl ether was distilled from $\mathrm{CaH}_{2}$. 1-dmso ${ }^{1}$ and 2-tmeda ${ }^{2}$ (Figure S19) were synthesized by reported procedures. NMR spectra were recorded on a Varian Unity INOVA 400 or a Bruker 400 and 600 spectrometer, respectively. ${ }^{1} \mathrm{H}$ and ${ }^{13} \mathrm{C}$ NMR chemical shifts were referenced to the solvent signals. High temperature NMR measurements of copolymers were performed in 1,1,2,2-tetrachloroethane- $\mathrm{d}_{2}$ at $130{ }^{\circ} \mathrm{C}$. Polymer molecular weights $\mathrm{M}_{\mathrm{n}}$ and degrees of polymerization $\mathrm{DP}_{\mathrm{n}}$ were determined by ${ }^{1} \mathrm{H}$ NMR spectroscopy from the integral of the repeat units versus the integral of the olefinic end groups on the assumption that every chain bears one unsaturated end group and one aliphatic end group. Differential scanning calorimetry (DSC) was performed on a Netzsch DSC 204 F1 instrument at a heating and cooling rate, respectively, of $10 \mathrm{~K} \mathrm{~min}^{-1}$. DSC data reported was determined from the second heating scan. Crystallinities were determined assuming a melt enthalpy of $293 \mathrm{~J} \mathrm{~g}^{-1}$ for $100 \%$ crystalline polyethylene. 


\section{Stoichiometric Studies}

\subsection{Insertion Studies of Propylene}

In order to study the reactivity of propylene towards neutral phosphinesulfonato palladium(II) catalysts, NMR experiments were carried out in a J. Young tube using 1-dmso as a catalyst precursor dissolved in $\mathrm{CD}_{2} \mathrm{Cl}_{2}$ at a concentration of $33 \mathrm{mM}$. The $J$. Young tube was pressurized with 1 atm propylene resulting in the dissolution of 3 equivalents of propylene relative to $\mathrm{Pd}(\mathrm{II})$. The reaction was monitored by the periodic acquisition of ${ }^{1} \mathrm{H}-$ NMR spectra at $25^{\circ} \mathrm{C}$ (Figure S1).

The signal of the Pd-Me resonance of the 1-dmso precursor at $\delta=0.3 \mathrm{ppm}$ decreases along with a new increasing resonance at $\delta=0.58 \mathrm{ppm}$ indicative for the 1,2 -insertion of propylene into the Pd-Me bond leading to an iso-butyl moiety with a characteristic doublet structure and a coupling constant of ${ }^{3} J_{\mathrm{HH}}=6.2 \mathrm{~Hz}$ for the methyl group protons. It should be noted that substantial amounts of this product were already formed in the first ${ }^{1} \mathrm{H}$ NMR spectrum recorded and it is subsequently consumed by consecutive propylene insertions (doublet resonances at $\delta=0.8-1.0 \mathrm{ppm}$ ) or $\beta$-hydride elimination to vinylidenes. With proceeding time, an increasing triplet resonance at $\delta=0.40 \mathrm{ppm}$ with a coupling constant of ${ }^{3} J_{\mathrm{HH}}=7.2 \mathrm{~Hz}$ could be observed, assigned to the methyl moiety of the Pd-sec-butyl formed by 2,1-insertion of propylene into the Pd-Me-bond of 1-dmso. In addition, the corresponding elimination products of the 2,1-insertion product can be observed. The quantitative time-dependent formation of products in this experiment is illustrated in Figure S2 from which it is evident that 1,2-insertion is significantly faster than 2,1-insertion. Furthermore, the signal growing at $0.21 \mathrm{ppm}$ could be assigned to traces of methane. However no quantification is possible due to its immediate and predominant presence in the NMR tube head space. Methane originates from the reaction of yet unreacted 1-dmso and Pd-hydride species ${ }^{3}$. The latter are formed in 
situ by $\beta$-hydride elimination of the insertion products and subsequent chain transfer as observed in the aforementioned formation of vinylidenes and internal olefins. In comparison to similar insertion experiments of 1-dmso with ethylene, an enhanced tendency for chain transfer for propylene compared to ethylene is observed since ethylene is consumed in a quasi-living fashion without any detectable amounts of olefins formed under these conditions. The reaction pathways observed in this insertion study of propylene with 1-dmso are summarized in Scheme S1.

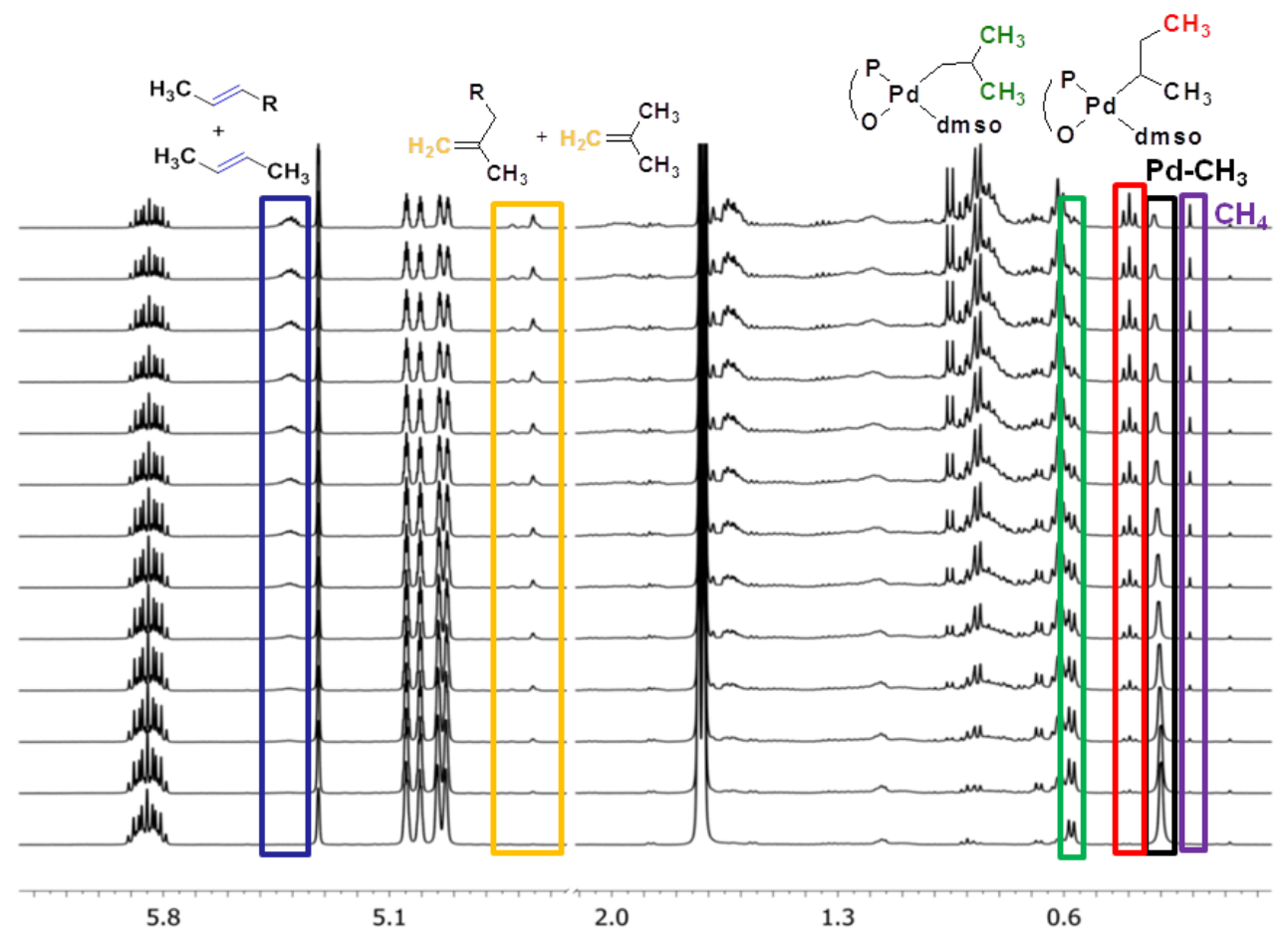

Figure S1. Stacked ${ }^{1} \mathrm{H}$ NMR spectra $\left(400 \mathrm{MHz}, 25^{\circ} \mathrm{C}, \mathrm{CD}_{2} \mathrm{Cl}_{2}\right)$ of the reaction of 1-dmso (33 mM) with 3 equivalents of propylene. Pd-Me (black); 1,2-insertion (green) 2,1-insertion product (red); internal olefins (blue), vinylidenes (orange) and methane (magenta). 


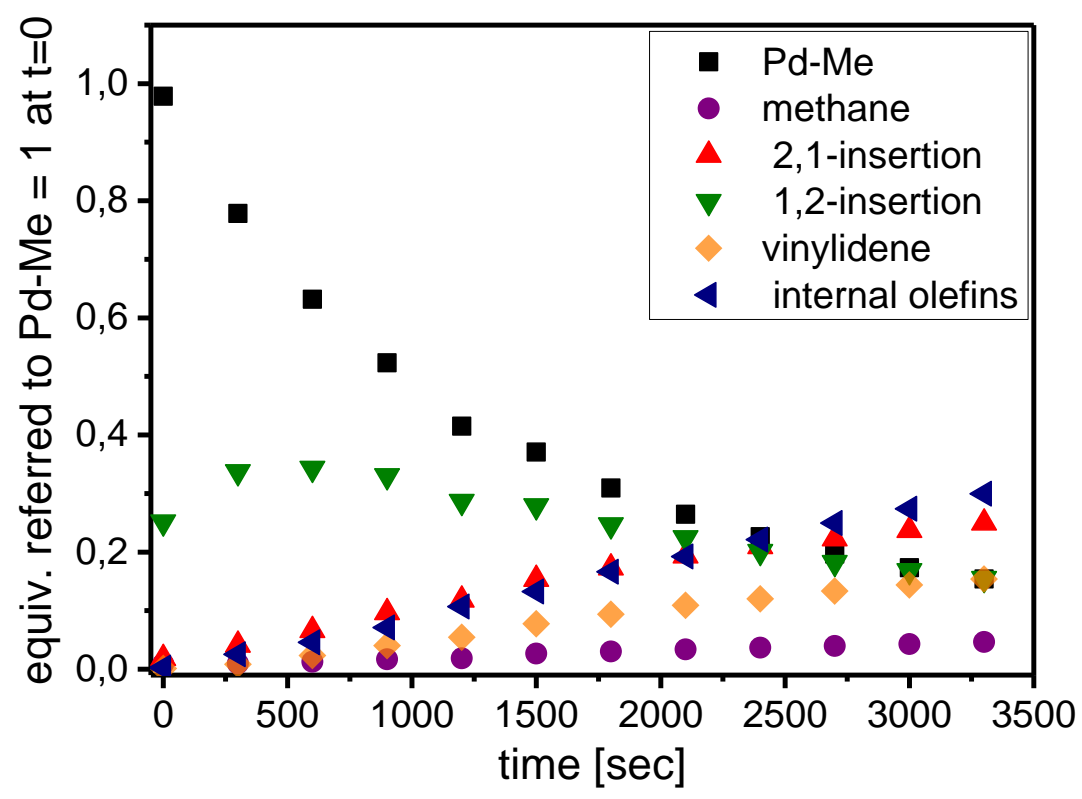

Figure S2. Time-dependent conversion of 1-dmso (black) via insertion of propylene to the 1,2-insertion product (green) and 2,1-insertion product (red) with concomitant formation of internal olefins (blue), vinylidenes (orange) and methane (magenta).

Scheme S1. ${ }^{1}$ H NMR Insertion studies of 1-dmso with propylene and illustration of possible routes to unsaturated end groups and methane.

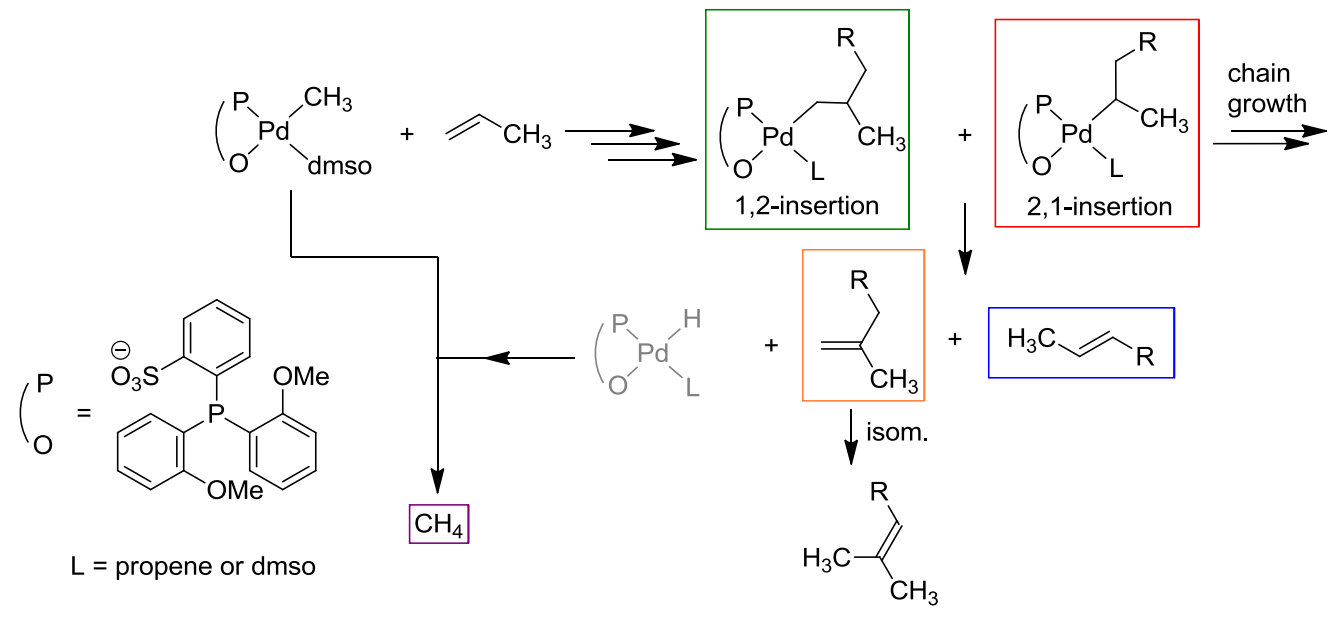




\subsection{Insertion Studies of 3-Methyl-1-Pentene}

3-methyl-1-pentene was studied in a NMR experiment for its ability to insert into the Pd-Me bond of 1-dmso. A NMR tube was charged with 1-dmso (65 mM) in $\mathrm{CD}_{2} \mathrm{Cl}_{2}$ at $25{ }^{\circ} \mathrm{C}$ and 3methyl-1-pentene (4.5 eq.) was added. ${ }^{1} \mathrm{H}$ NMR spectra were acquired periodically every 10 minutes. Insertion takes place as can be seen in Figure S3 from the decrease of the resonance of the methyl group protons in Pd-Me at $\delta=0.33 \mathrm{ppm}$ and the consumption of 3-methyl-1pentene as its proton signals at $4.9 \mathrm{ppm}$ and $5.73 \mathrm{ppm}$ are decreasing. Almost all Pd-Me species seem to be initated by insertion since only small traces of methane can be observed at $\delta=0.22 \mathrm{ppm}$ (although it has to be kept in mind that quantification of methane is difficult due to its rapid loss to the NMR tube head space). The increasing doublet at $\delta=0.40 \mathrm{ppm}$ corresponds to 1,2-insertion into the Pd-methyl-bond. Furthermore, after almost all Pd-Me is consumed, another multiplett signal arises in the region characteristic for internal 3substituted olefins at $\delta=5.2 \mathrm{ppm}$. Internal olefins are only formed by 2,1-insertion into either the $\mathrm{Pd}-\mathrm{Me}$ or $\mathrm{Pd}-\mathrm{H}$ species and subsequent $\beta$-hydride elimination. Since all $\mathrm{Pd}-\mathrm{Me}$ is consumed at that time and the signal increases even further after the kinetic experiment, the internal olefin originates from $\beta$-hydride elimination after 2,1-insertion into the $\mathrm{Pd}-\mathrm{H}$ species. 

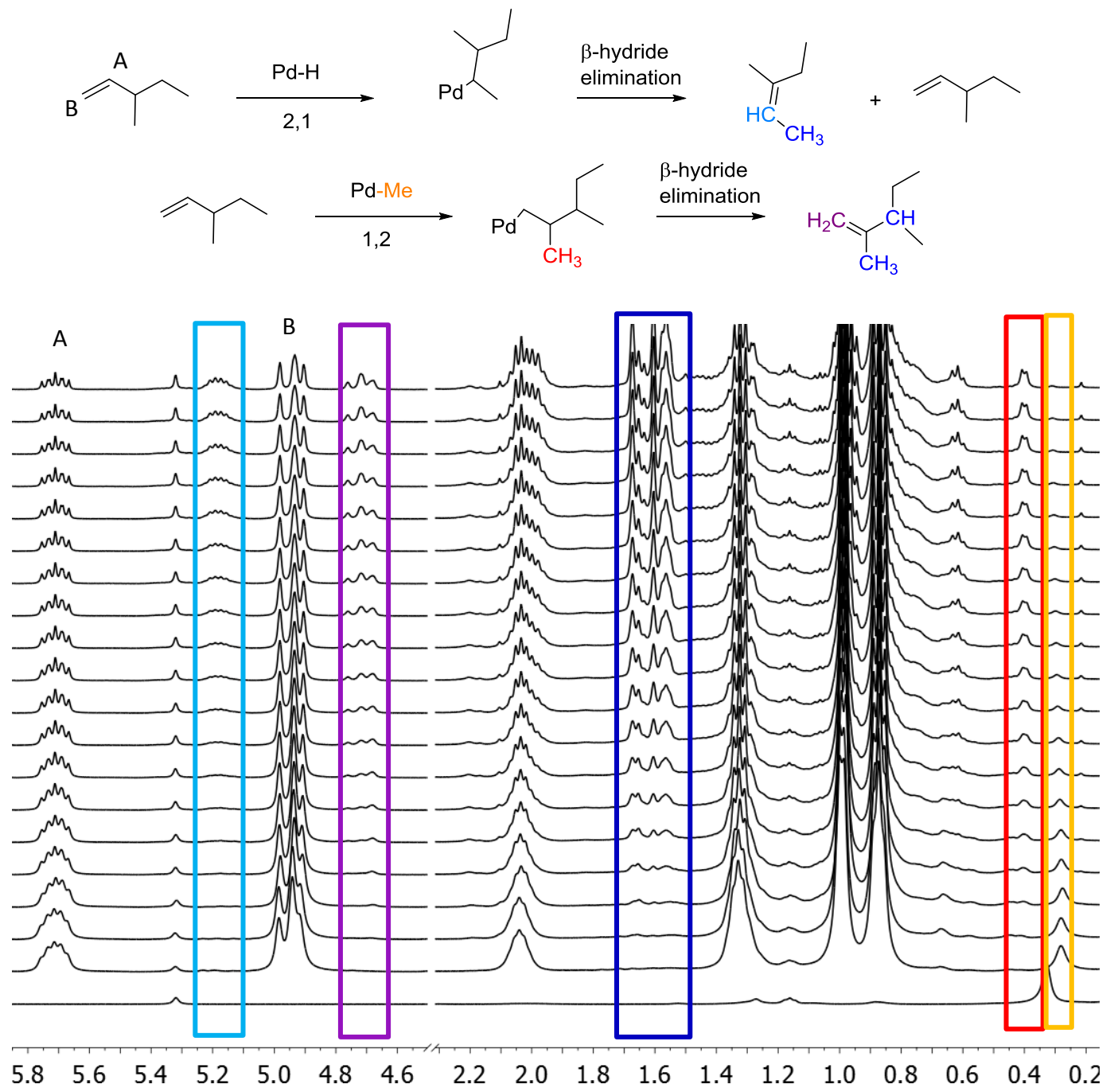

Figure S3. Stacked ${ }^{1} \mathrm{H}$ NMR spectra $\left(400 \mathrm{MHz}, 25^{\circ} \mathrm{C}, \mathrm{CD}_{2} \mathrm{Cl}_{2}\right)$ of the reaction of 1-dmso $(65 \mathrm{mM})$ with 4.5 equivalents of 3-methyl-1-pentene.

This assumption could be confirmed by ${ }^{1} \mathrm{H}-{ }^{1} \mathrm{H}$ gCOSY and ${ }^{1} \mathrm{H}^{13}{ }^{13} \mathrm{C}$ gHSQC spectra of the resulting reaction mixture (Figure S4 and Figure S5) which show that no disubstituted internal olefins are formed. Over the course of the experiment 3-methyl-1-pentene is isomerized to the trisubstituted internal olefins B and vinylidene C (Scheme S2). 


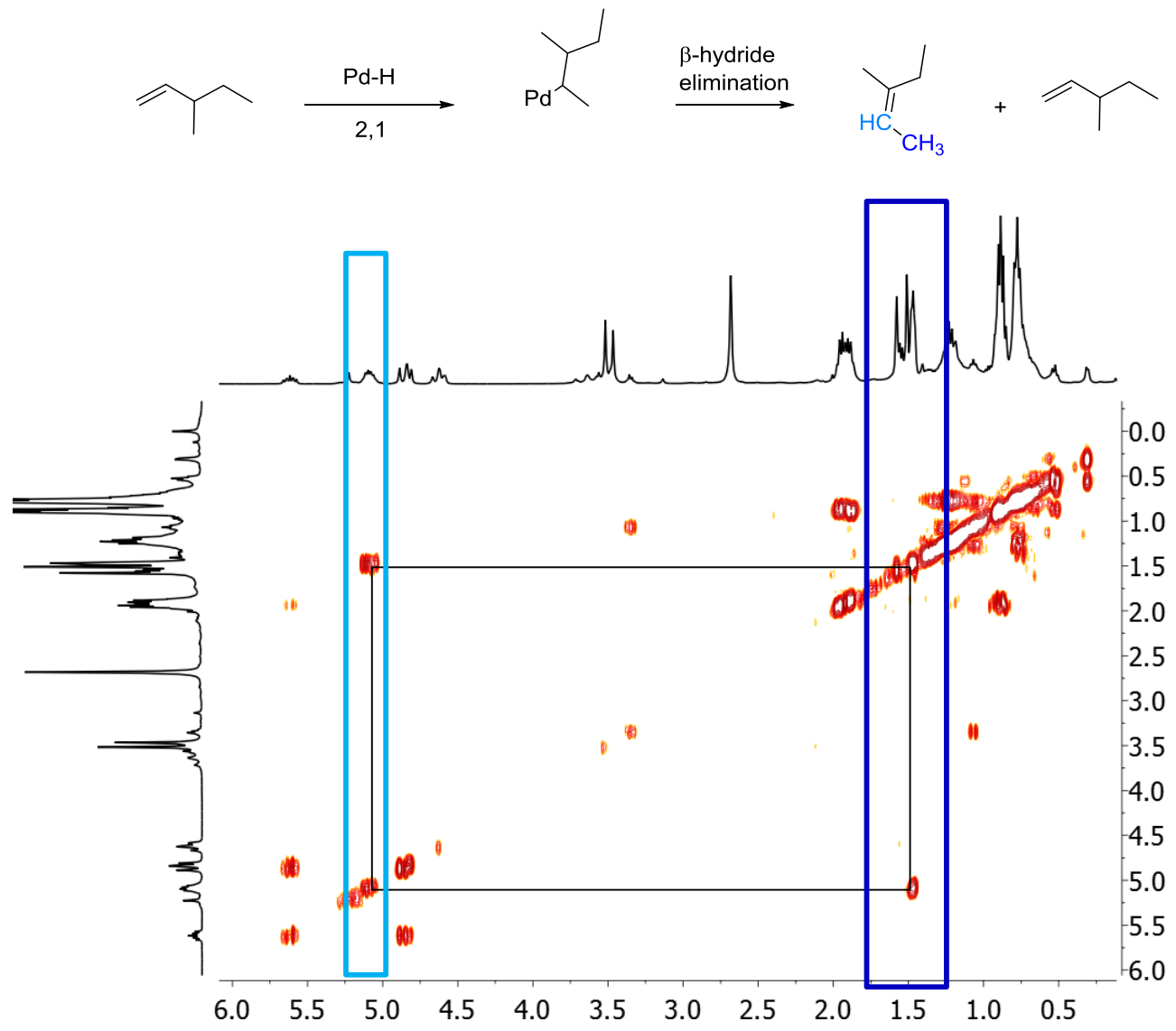

Figure S4. ${ }^{1} \mathrm{H}-{ }^{1} \mathrm{H}$-gCOSY spectrum $\left(400 \mathrm{MHz}, 25{ }^{\circ} \mathrm{C}, \mathrm{CD}_{2} \mathrm{Cl}_{2}\right)$ for the reaction of 1-dmso (65 mM) with 4.5 equivalents of 3-methyl-1-pentene.

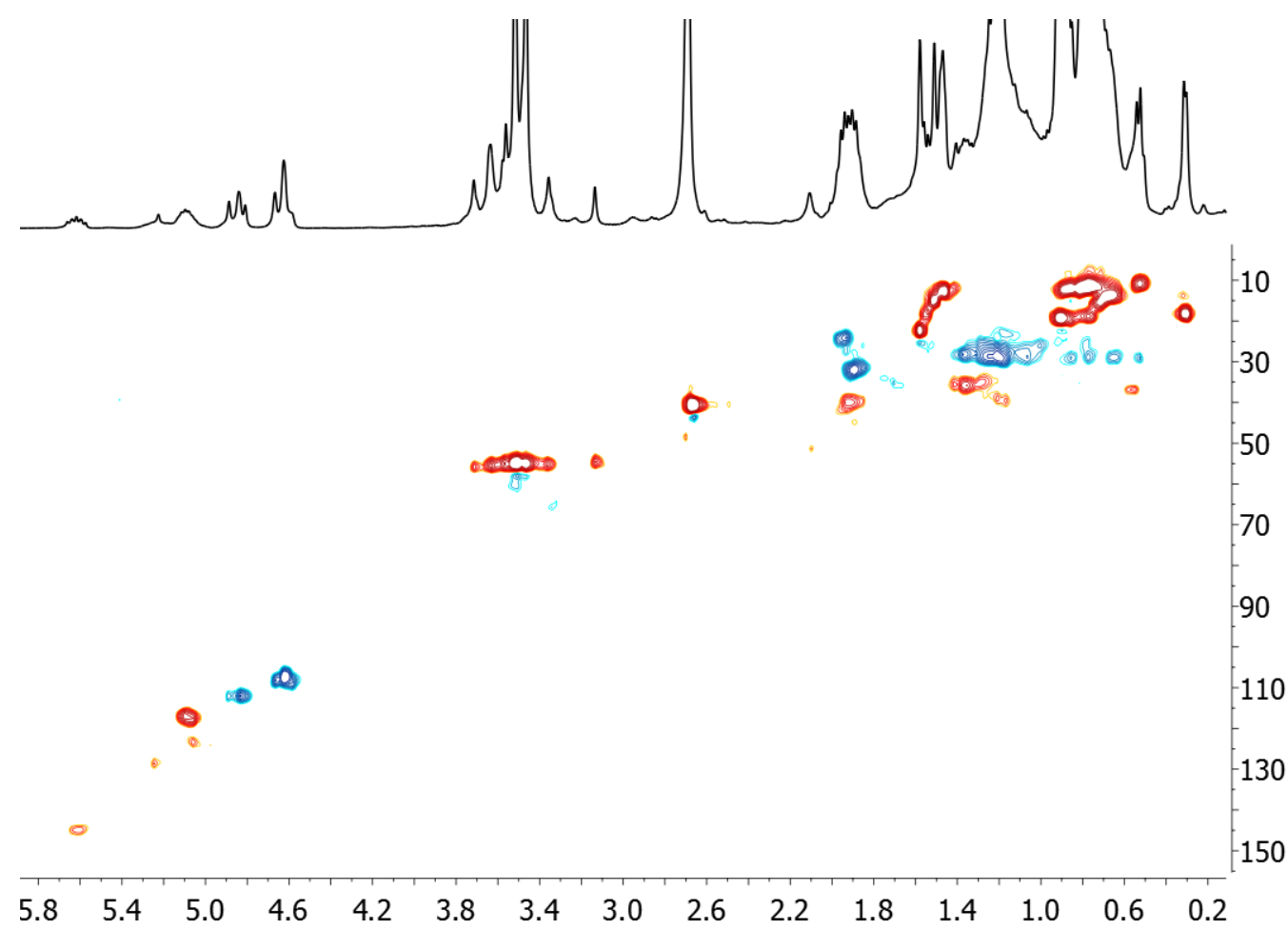


Figure S5. ${ }^{1} \mathrm{H}_{-}{ }^{13} \mathrm{C}$-gHSQC spectrum $\left(400 \mathrm{MHz}, 25{ }^{\circ} \mathrm{C}, \mathrm{CD}_{2} \mathrm{Cl}_{2}\right)$ for the reaction of 1-dmso $(65 \mathrm{mM})$ with 4.5 equivalents of 3-methyl-1-pentene.

Scheme S2. Insertion modes observed for the insertion of 3-methyl-1-pentene into the Pd-Me bond of 1-dmso (grey: pathway is not observed).
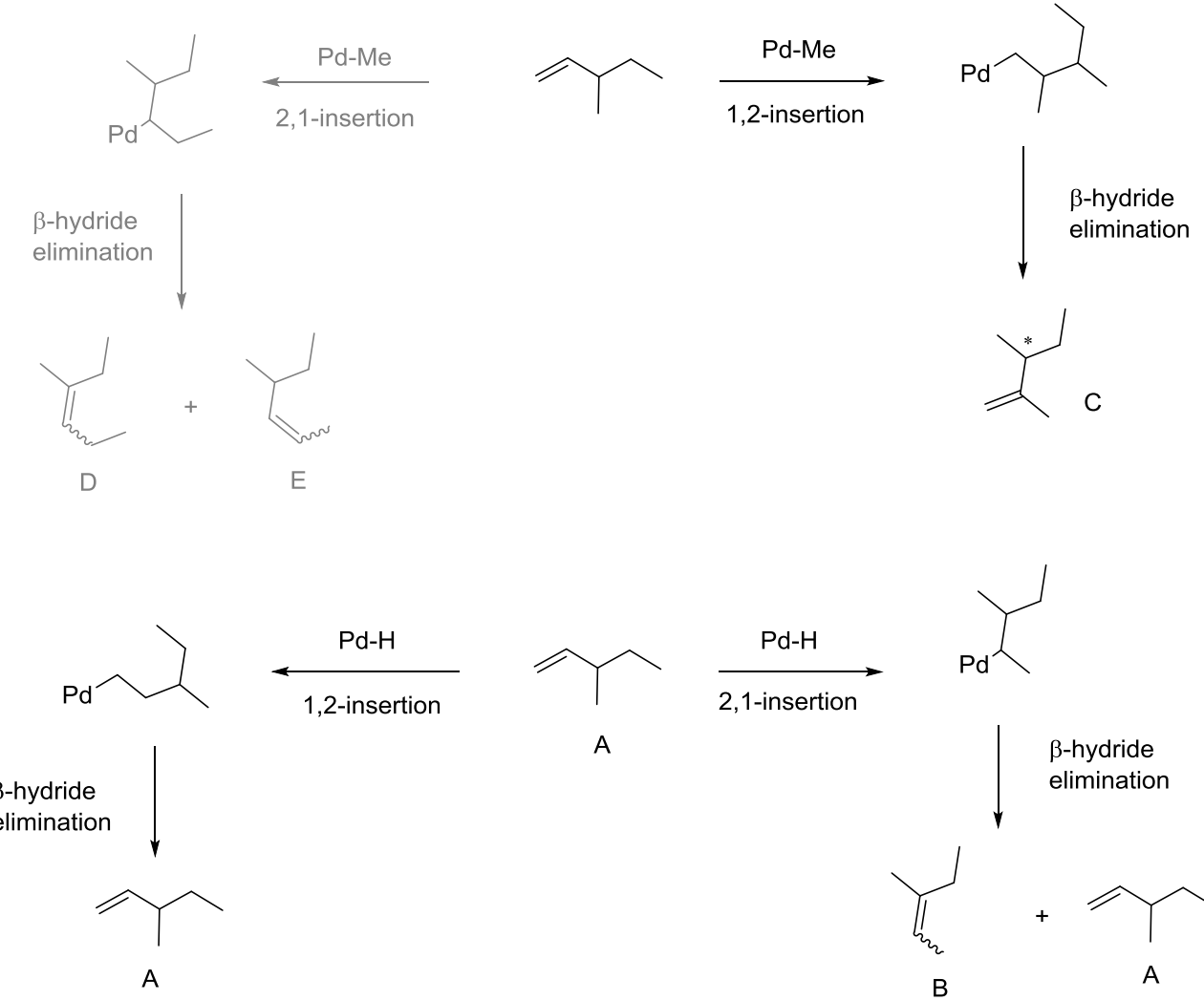

\subsection{Insertion Studies of Allyl Acetate}

A NMR tube was charged with 1-dmso $(65 \mathrm{mM})$ in $\mathrm{CD}_{2} \mathrm{Cl}_{2}$ at $25{ }^{\circ} \mathrm{C}$ and 6 equivalents of allyl acetate were added. ${ }^{1} \mathrm{H}$ NMR spectra were acquired periodically every 10 minutes (Figure S6). The decrease of the Pd-Me signal at $\delta=0.32 \mathrm{ppm}$ indicates insertion to occur. The increasing doublet (B1 in Figure S7) at $\delta=0.57 \mathrm{ppm}$ results from 1,2-insertion into the Pd-Me bond and the triplet resonance (A1 in Figure S7) at $\delta=0.71 \mathrm{ppm}$ results from 2,1insertion into the Pd-Me-bond, as confirmed by a ${ }^{1} \mathrm{H}-{ }^{1} \mathrm{H}$ gCOSY spectrum (Figure S7). The $\beta$ hydride elimination product from the 2,1-insertion can be identified as the doublet of doublet 
at $\delta=1.66 \mathrm{ppm}$. The $\beta$-hydride elimination product from the 1,2 -insertion is not observable due to the overlap with other signals in this region.

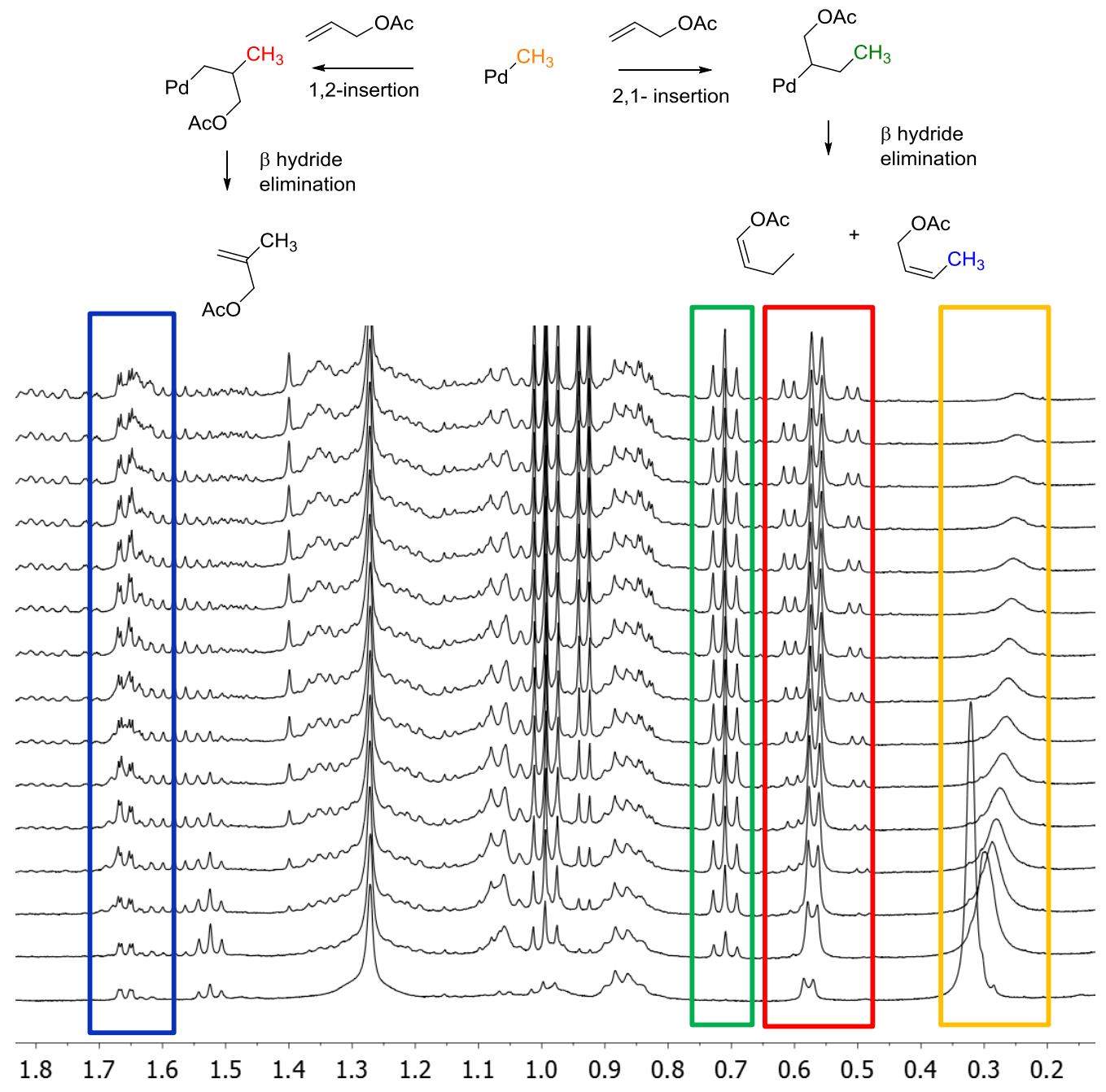

Figure S6. Stacked ${ }^{1} \mathrm{H}$ NMR spectra $\left(400 \mathrm{MHz}, 25^{\circ} \mathrm{C}, \mathrm{CD}_{2} \mathrm{Cl}_{2}\right)$ of the reaction of 1-dmso $(65 \mathrm{mM})$ with 6 equivalents of allyl acetate. 


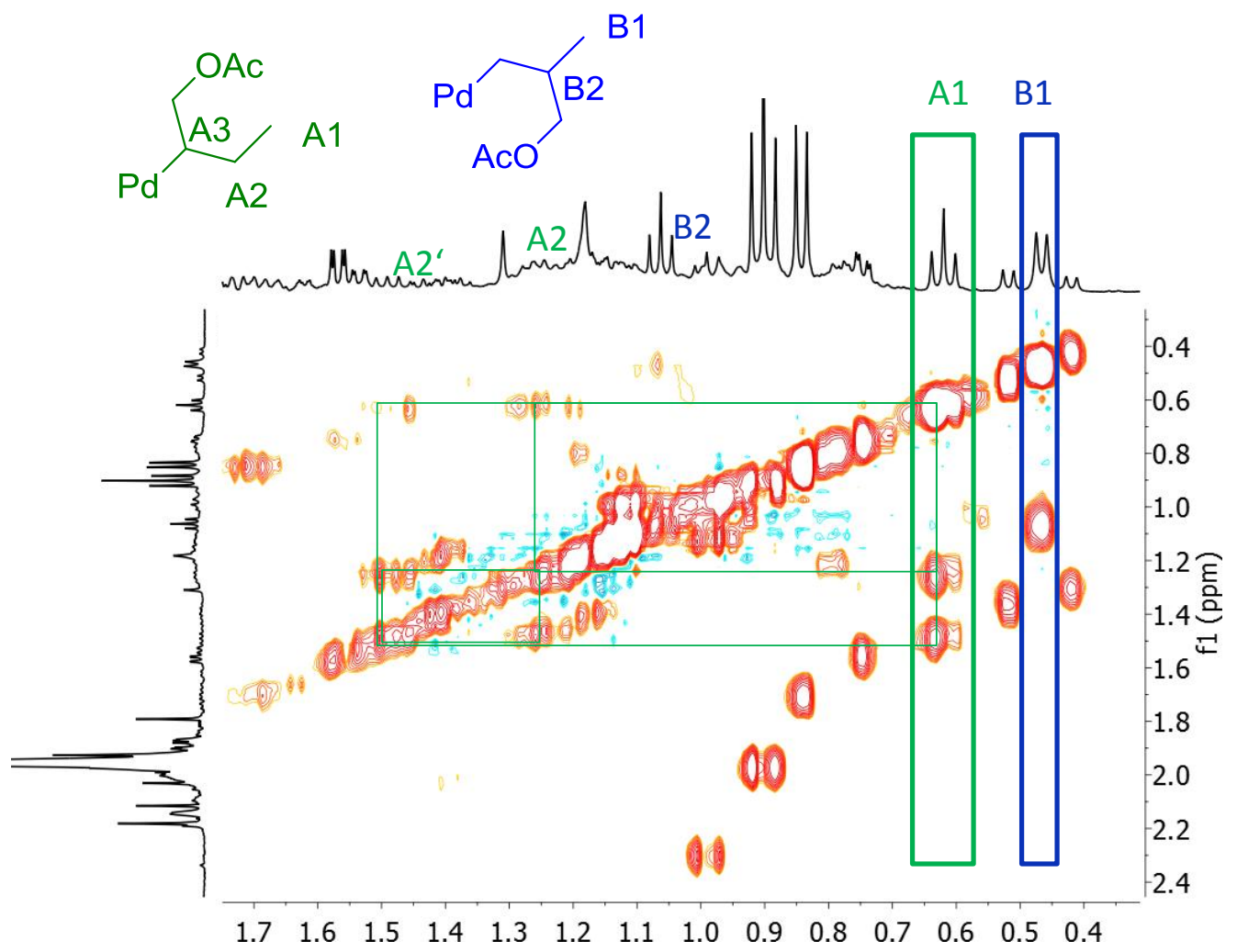

Figure S7. ${ }^{1} \mathrm{H}-{ }^{1} \mathrm{H}$ gCOSY $\left(400 \mathrm{MHz}, 25{ }^{\circ} \mathrm{C}, \mathrm{CD}_{2} \mathrm{Cl}_{2}\right)$ for the reaction of 1-dmso $(65 \mathrm{mM})$ with 6 equivalents of allyl acetate. 


\subsection{Insertion Studies of Vinyl Acetate}

A NMR tube was charged with 1-dmso $(67 \mathrm{mM})$ in $\mathrm{CD}_{2} \mathrm{Cl}_{2}$ at $25{ }^{\circ} \mathrm{C}$ and 15 equivalents of vinyl acetate were added. ${ }^{1} \mathrm{H}$ NMR spectra were acquired periodically every 10 minutes (Figure S8 and Figure S9). The signal for the methyl group protons in Pd-Me at $\delta=0.32 \mathrm{ppm}$ decreases through 2,1- and 1,2-insertion of vinyl acetate into the Pd-Me-bond. The triplet at $\delta$ $=0.65 \mathrm{ppm}$ corresponds to the resonance of the methyl protons of the product complex of the first 2,1-insertion (Figure S10).
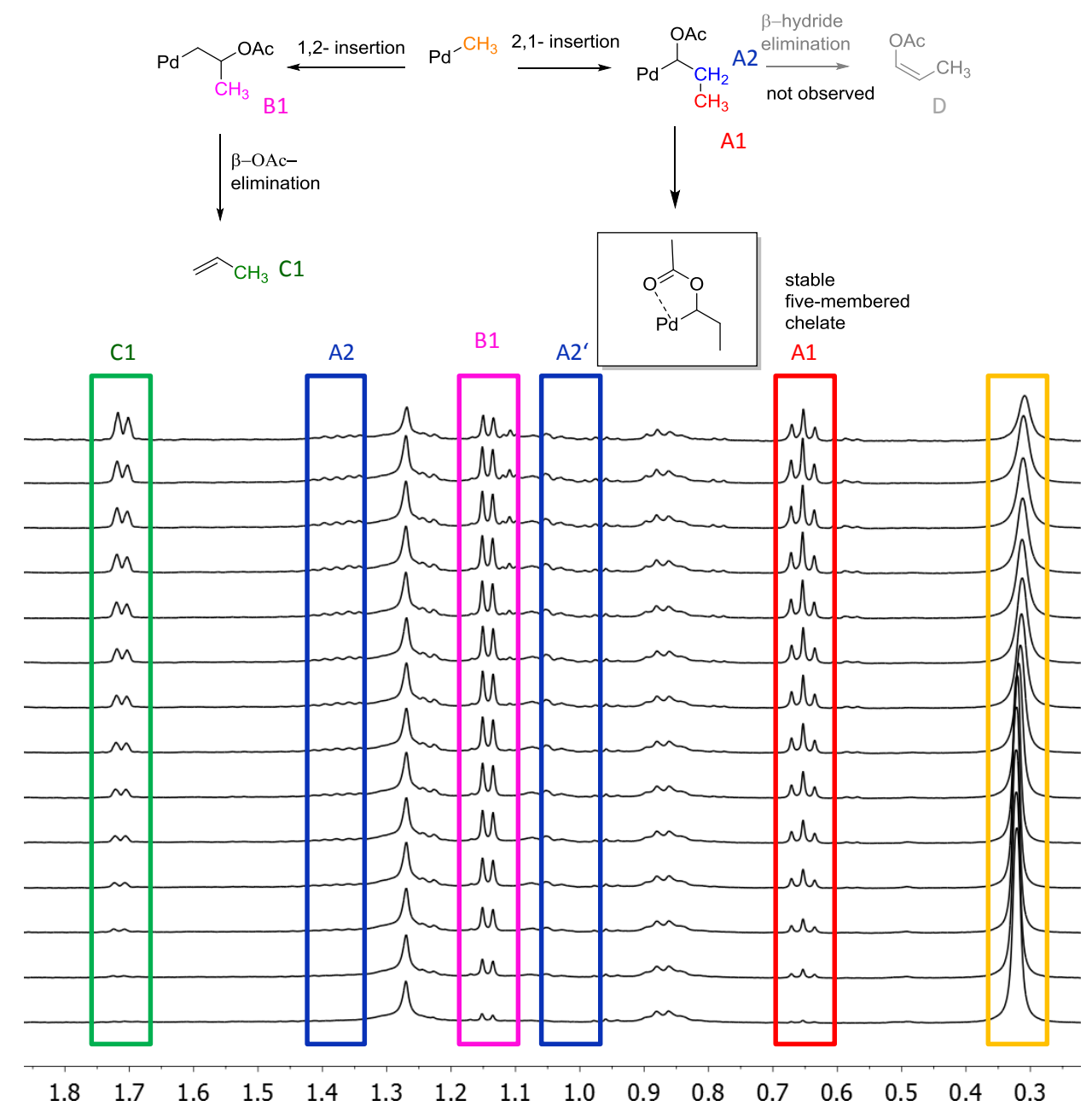

Figure S8. Stacked ${ }^{1} \mathrm{H}$ NMR (400 MHz, $\left.25{ }^{\circ} \mathrm{C}, \mathrm{CD}_{2} \mathrm{Cl}_{2}\right)$ spectra between 0.2 and $1.8 \mathrm{ppm}$ of the reaction of 1-dmso $(67 \mathrm{mM})$ with 15 equivalents of vinyl acetate. 


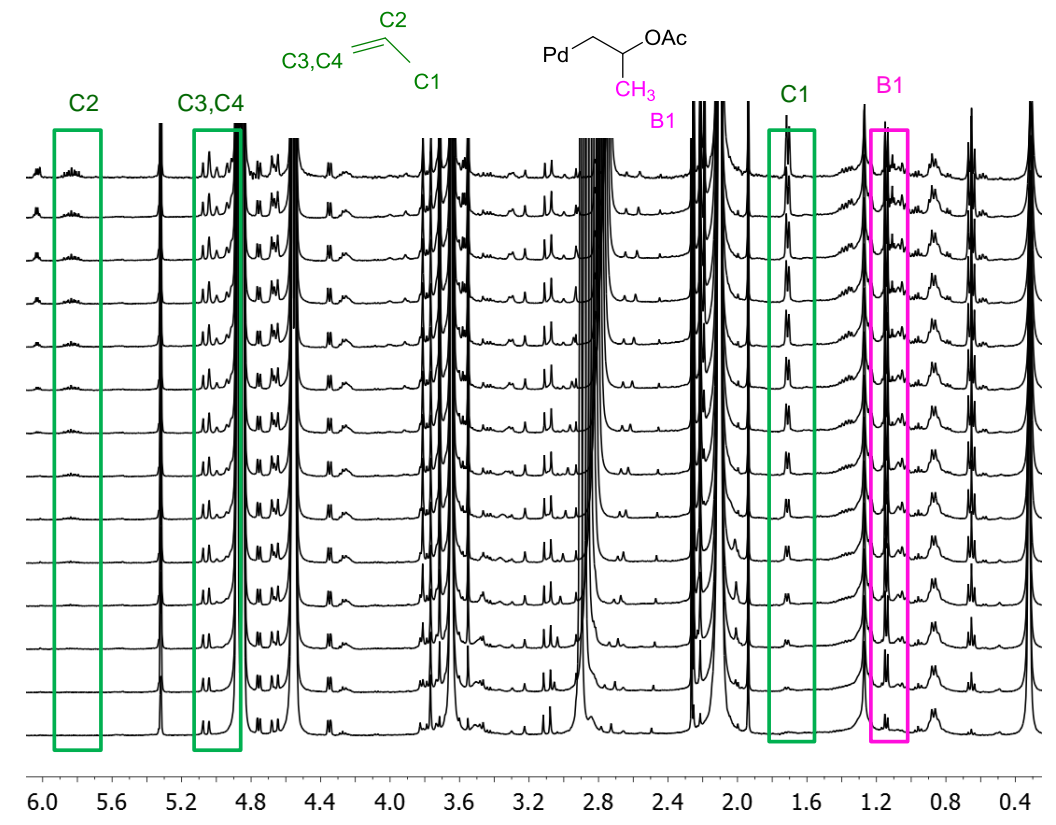

Figure S9.Stacked ${ }^{1} \mathrm{H}$ NMR $\left(400 \mathrm{MHz}, 25{ }^{\circ} \mathrm{C}, \mathrm{CD}_{2} \mathrm{Cl}_{2}\right)$ spectra of the reaction of 1-dmso (67 $\mathrm{mM}$ ) with 15 equivalents of vinyl acetate.

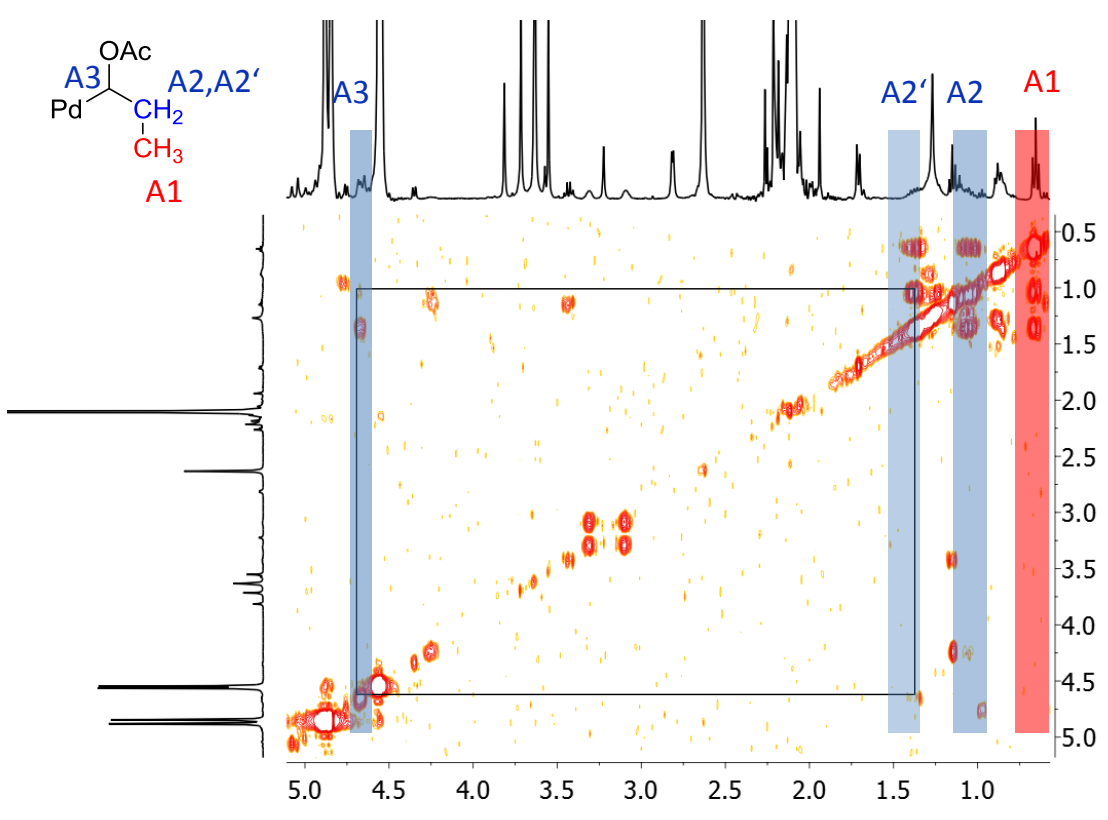

Figure S10. ${ }^{1} \mathrm{H}-1 \mathrm{H}$ gCOSY $\left(400 \mathrm{MHz}, 25{ }^{\circ} \mathrm{C}, \mathrm{CD}_{2} \mathrm{Cl}_{2}\right)$ of the reaction of 1-dmso $(67 \mathrm{mM})$ with 15 equivalents of vinyl acetate. 
The doublet at $1.15 \mathrm{ppm}$ can be ascribed to the resonance of the methyl protons of the first 1,2-insertion product. After 4 days at room temperature, the doublet at $1.15 \mathrm{ppm}$ had vanished completely while the triplet at $0.65 \mathrm{ppm}$ was still present in considerable amounts due to the stability of the 5-ring chelate formed by the first 2,1-insertion product via intramolecular bonding of the carbonyl group to palladium. The stable ring chelate formed by the first 2,1insertion product prevents $\beta$-hydride elimination to propenyl acetate (D in Figure S8) which was not observed in the ${ }^{1} \mathrm{H}$ NMR spectra (pathway in grey in Figure S8). The doublet of a triplet at $1.73 \mathrm{ppm}$ was ascribed to the methyl group protons of propylene and confirmed by reference spectra and a 1H-1H 1D-TOCSY spectrum (

Figure S11).

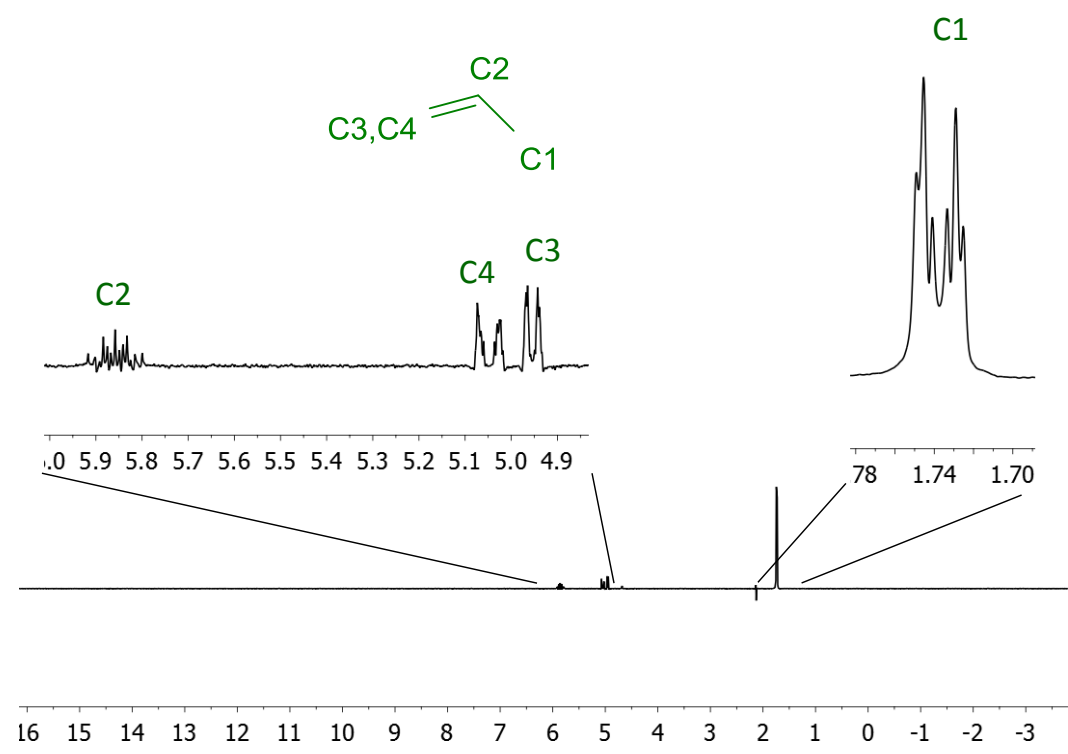

Figure S11. ${ }^{1} \mathrm{H}-{ }^{1} \mathrm{H}$ 1D-TOCSY $\left(400 \mathrm{MHz}, 25{ }^{\circ} \mathrm{C}, \mathrm{CD}_{2} \mathrm{Cl}_{2}\right.$, excitation at $\left.1.737 \mathrm{ppm}\right)$ confirming the formation of propylene during the reaction of 1-dmso (67 mM) with 15 equivalents of vinyl acetate.

Propylene is formed by $\beta$-OAc-elimination of the first 1,2 -insertion product into the Pd-Me bond. Hence, vinyl acetate inserts both in a 1,2- and a 2,1-fashion into the Pd-Me bond. Quantification of 1,2- vs. 2,1-insertion products is not possible due to the rapid $\beta$-hydride 
elimination observed for the 1,2-insertion product. However, integral analysis of the periodically acquired ${ }^{1} \mathrm{H}$ NMR spectra shows a much faster increase for the 1,2-insertion product and the propylene formation compared to 2,1-insertion indicating a preference for 1,2-over 2,1- insertion into the Pd-Me bond.

\subsection{Insertion Studies of Allyl Diethyl Phosphonate}

A NMR tube was charged with 1-dmso $(72 \mathrm{mM})$ in $\mathrm{CD}_{2} \mathrm{Cl}_{2}$ at $25{ }^{\circ} \mathrm{C}$ and 30 equivalents of allyl diethyl phosphonate were added. ${ }^{1} \mathrm{H}$ and ${ }^{31} \mathrm{P}$ NMR spectra were acquired directly after addition, after $2 \mathrm{~h}$ and after $20 \mathrm{~h}$. Insertion of allyl diethyl phosphonate into the Pd-Me bond proceeded rather slowly. After $20 \mathrm{~h}$ the reaction was complete as evidenced by the disappearance of the $\mathrm{Pd}-\mathrm{CH}_{3}$ resonance at $\delta=0.19 \mathrm{ppm}$ in the ${ }^{1} \mathrm{H}$ NMR spectrum (Figure S12). Insertion occured by both 1,2- and 2,1-insertion in a 1:1 ratio. The triplet at $0.26 \mathrm{ppm}$ can be ascribed to the methyl proton resonance (A1, red in Figure S12 and Figure S13) in the 2,1-insertion product and the doublet of a doublet (B1, blue in Figure S12 and Figure S13) to the methyl proton resonance in the 1,2-insertion product. $\beta$ hydride elimination was not observed indicating the presence of stable chelates via coordination of the $\mathrm{P}=\mathrm{O}$ group to the $\mathrm{Pd}$ as also observed for vinyl diethyl phosphonate. ${ }^{4}$ Furthermore, dmso and free allyl diethyl phosphonate is removed upon work up of the complexes supporting the assumption of present intramolecular coordination of the $\mathrm{P}=\mathrm{O}$-motifs. 


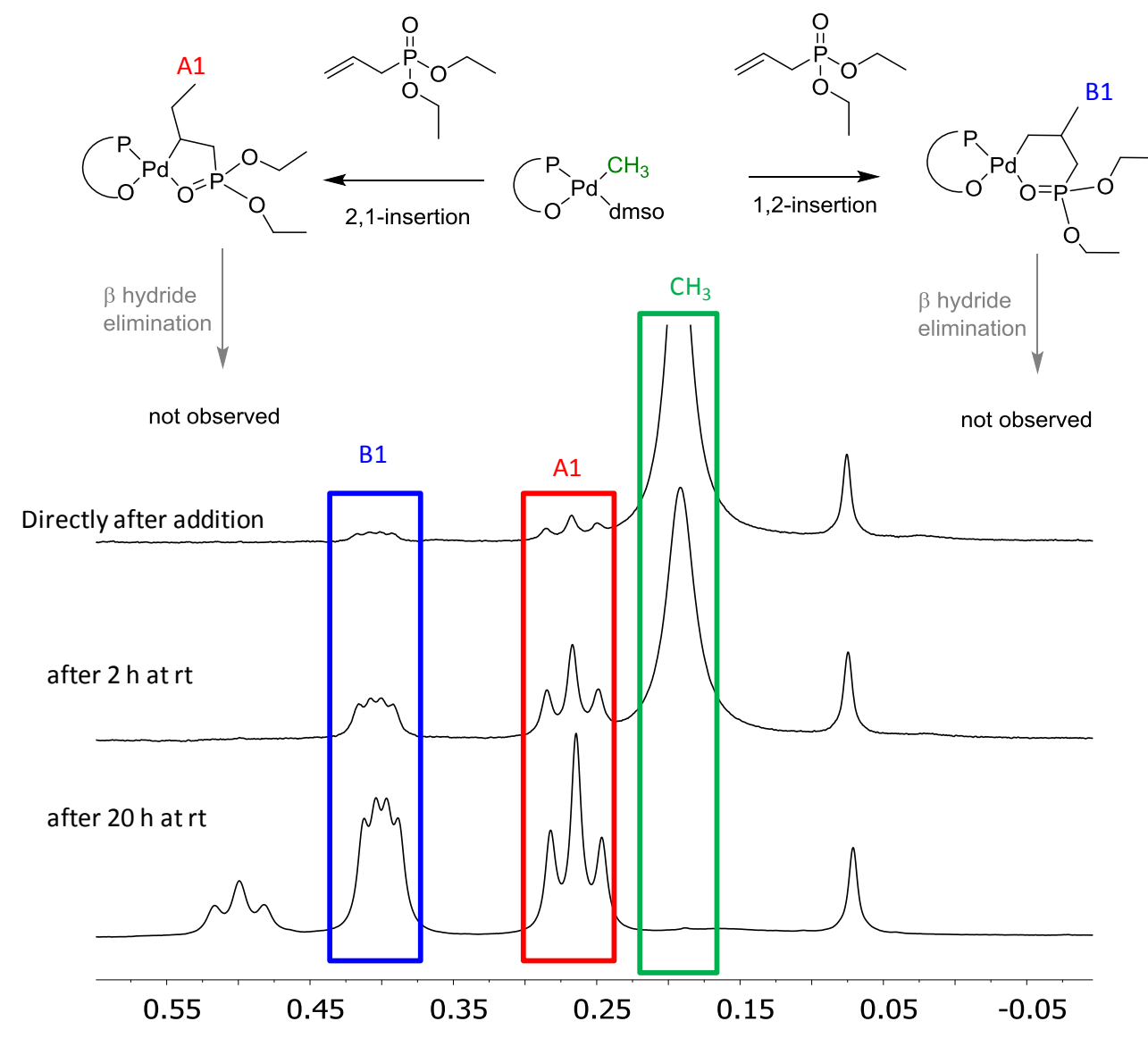

Figure S12. Stacked ${ }^{1} \mathrm{H}$ NMR spectra $\left(400 \mathrm{MHz}, 25{ }^{\circ} \mathrm{C}, \mathrm{CD}_{2} \mathrm{Cl}_{2}\right)$ for the insertion of allyl diethyl phosphonate (30 eq.) into 1-dmso (72 mM).

The insertion products were worked up by precipitation of the reaction mixture in diethyl ether which yielded about $15 \mathrm{mg}$ of a 1:1 mixture of the 1,2-and 2,1-insertion products (Figure S13). The same insertion ratio was determined before work up of the reaction mixture, showing that no insertion product is lost upon work up. 


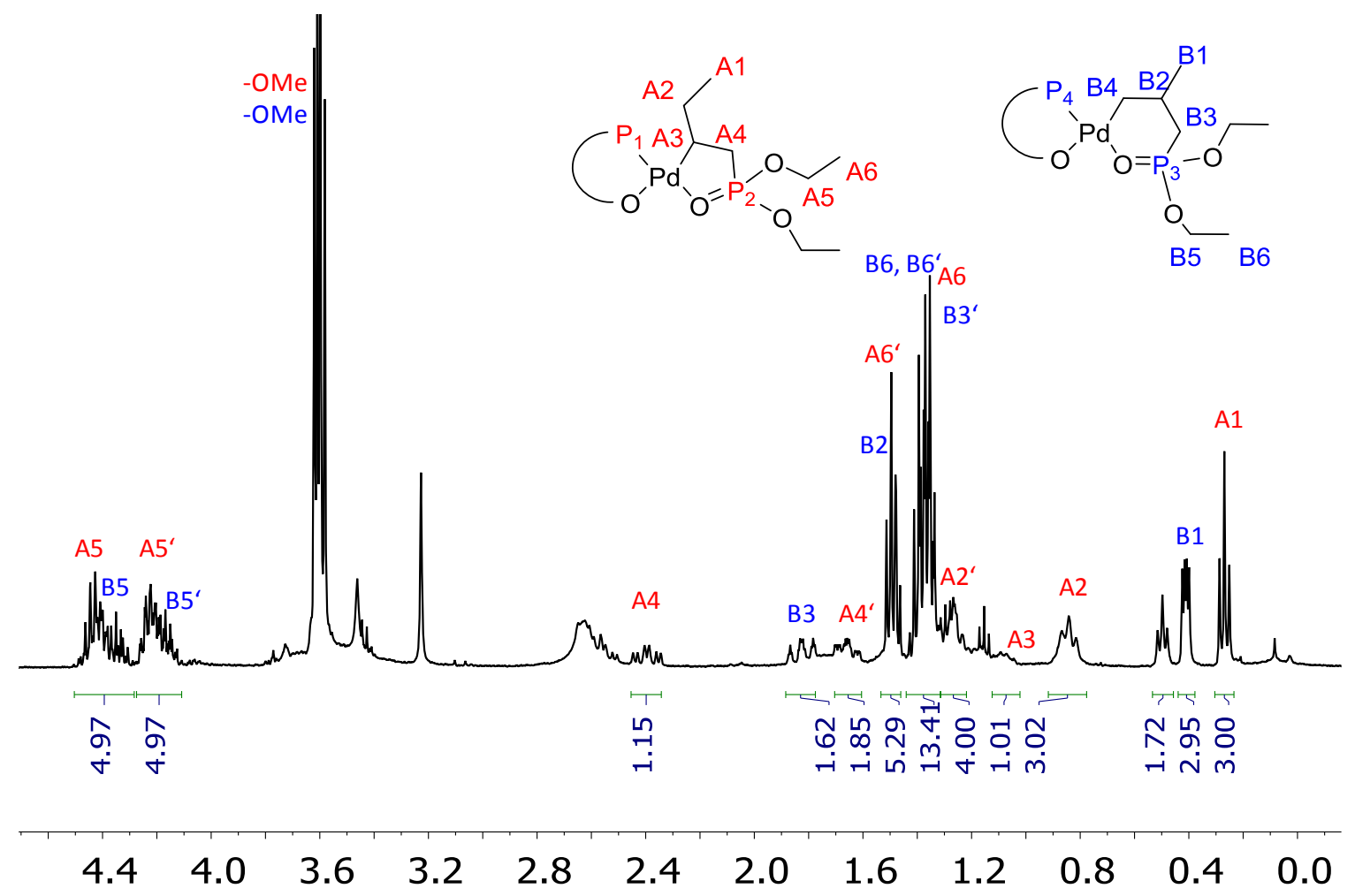

Figure S13. ${ }^{1} \mathrm{H}$ NMR spectrum (top) and ${ }^{1} \mathrm{H}\left\{{ }^{31} \mathrm{P}\right\}$ NMR spectrum (bottom) $\left(400 \mathrm{MHz}, 25{ }^{\circ} \mathrm{C}\right.$, $\mathrm{CD}_{2} \mathrm{Cl}_{2}$ ) for the isolated insertion products of allyl diethyl phosphonate into 1-dmso.

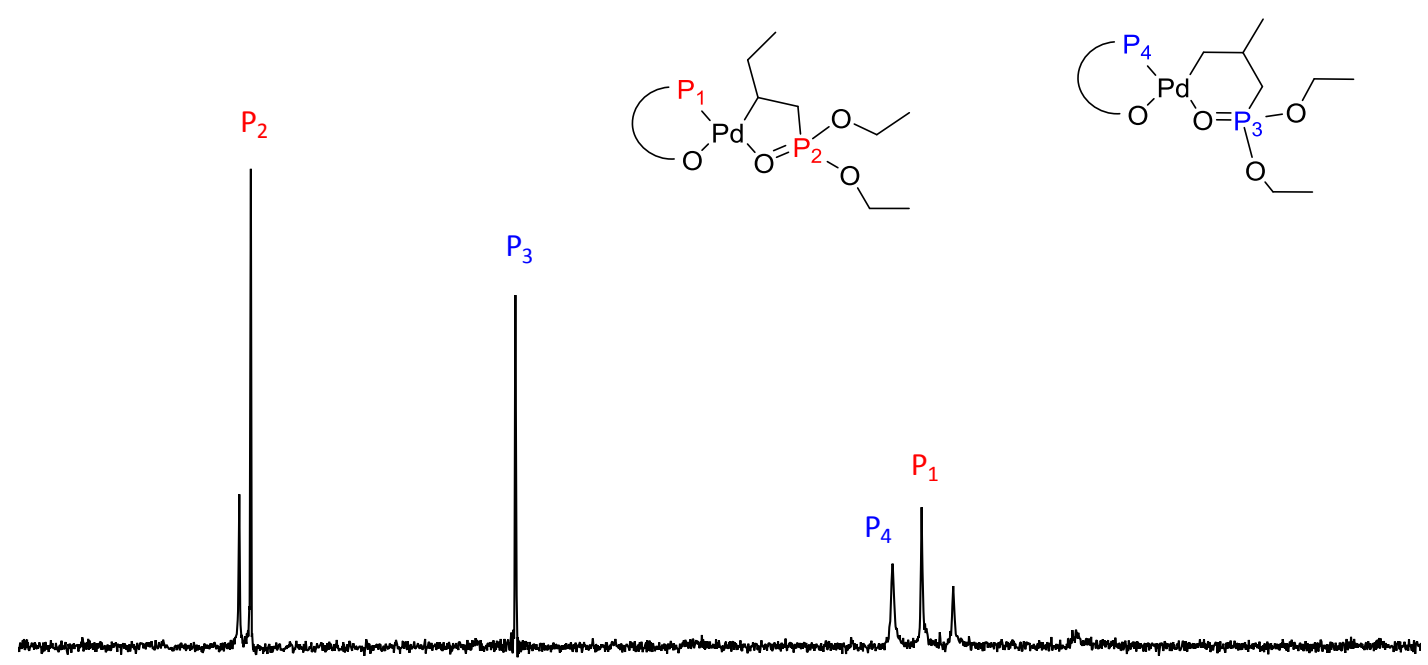

$\begin{array}{lllllllllllllllllllll}53 & 51 & 49 & 47 & 45 & 43 & 41 & 39 & 37 & 35 & 33 & 31 & 29 & 27 & 25 & 23 & 21 & 19 & 17 & 15 & 13\end{array}$

Figure S14. ${ }^{31} \mathrm{P}$ NMR spectrum $\left(162 \mathrm{MHz}, 25{ }^{\circ} \mathrm{C}, \mathrm{CD}_{2} \mathrm{Cl}_{2}\right)$ of the 1,2- and 2,1-insertion products for the reaction of allyl diethyl phosphonate with 1-dmso. 


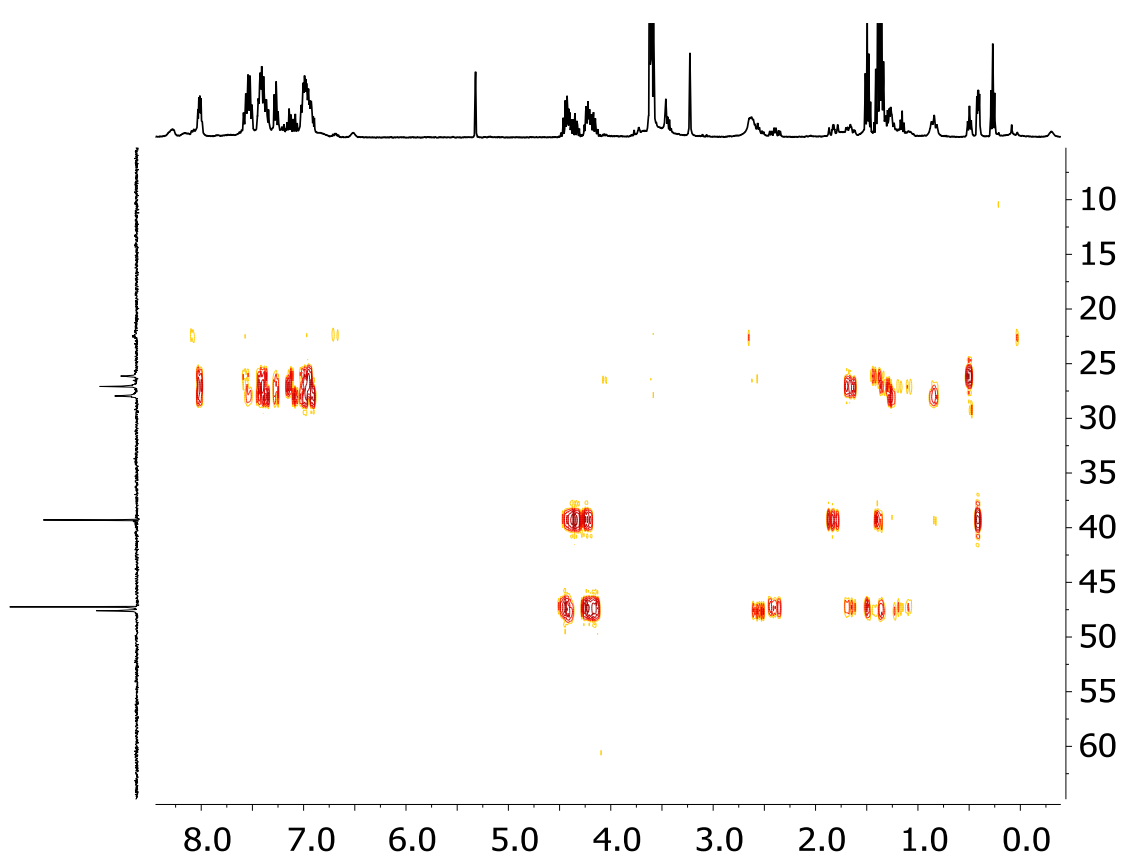

Figure S15. ${ }^{1} \mathrm{H}_{-}{ }^{31} \mathrm{P}$ HMBC spectrum (400 and $162 \mathrm{MHz}, 25^{\circ} \mathrm{C}, \mathrm{CD}_{2} \mathrm{Cl}_{2}$ ) of the $1,2-$ and $2,1-$ insertion products from the reaction of allyl diethyl phosphonate with 1-dmso.

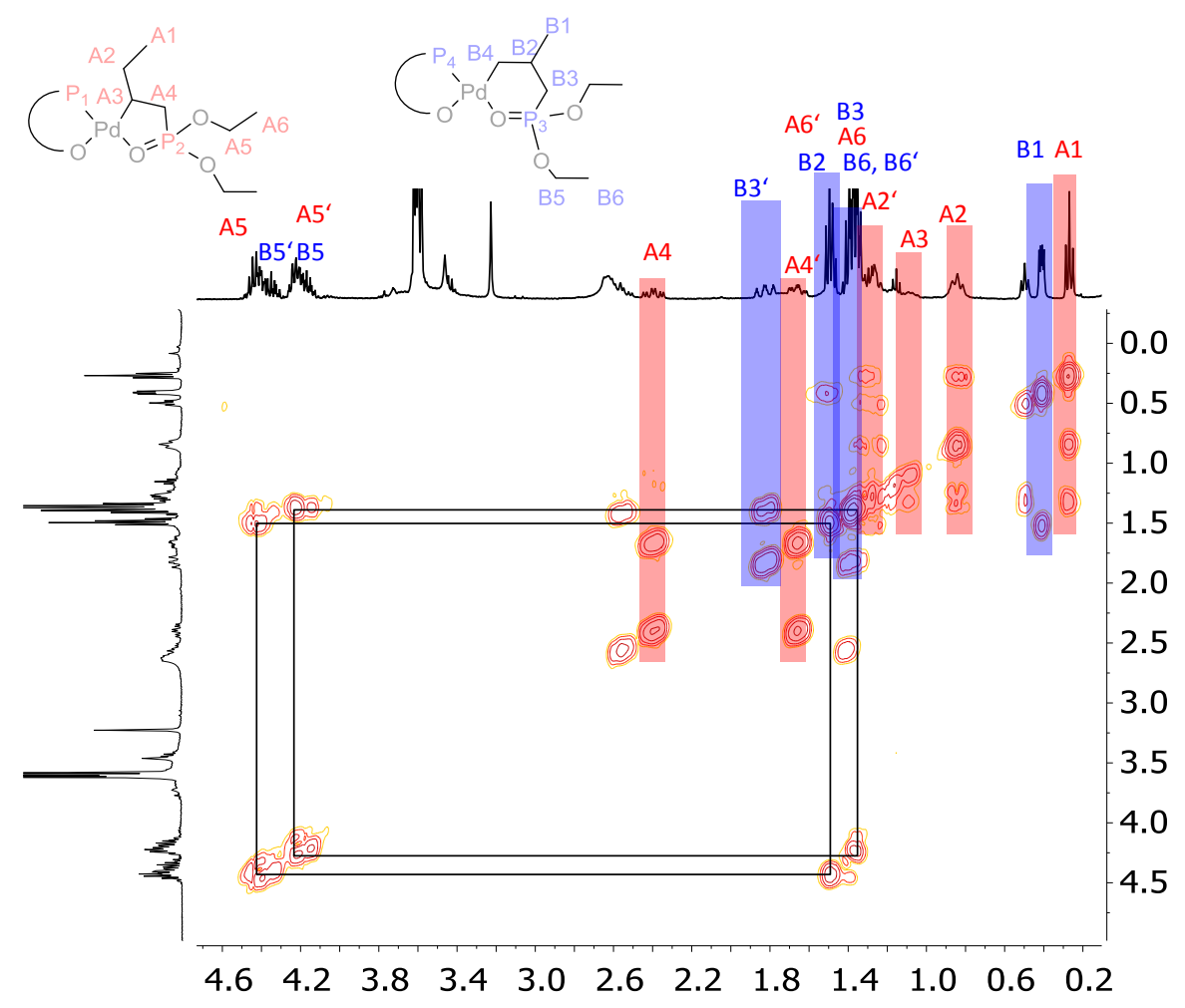

Figure S16. ${ }^{1} \mathrm{H}-{ }^{1} \mathrm{H}$ COSY spectrum $\left(400 \mathrm{MHz}, 25{ }^{\circ} \mathrm{C}, \mathrm{CD}_{2} \mathrm{Cl}_{2}\right)$ of the 1,2- and 2,1-insertion products from the reaction of allyl diethyl phosphonate with 1-dmso. 


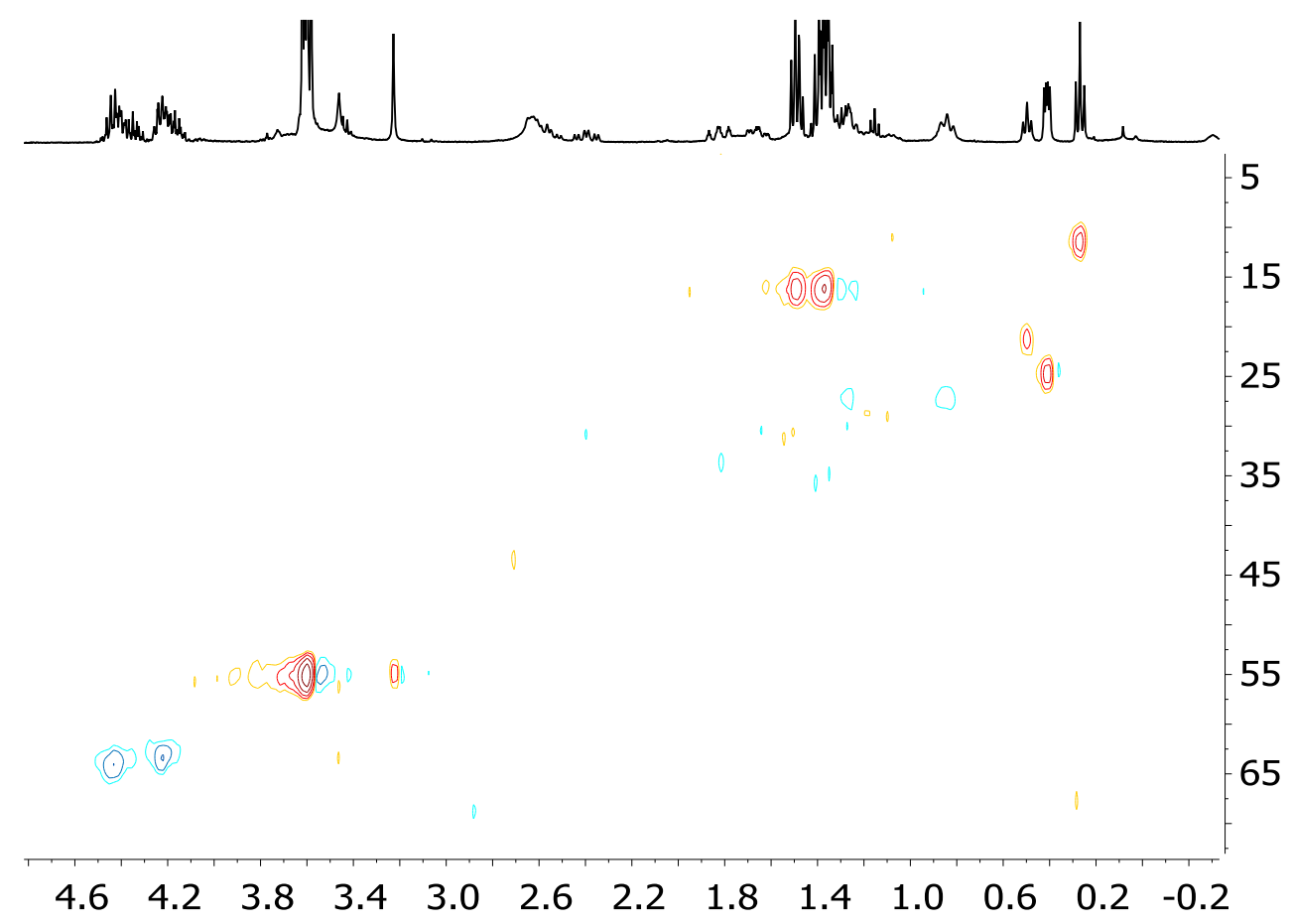

Figure S17. ${ }^{1} \mathrm{H}-{ }^{13} \mathrm{C} \mathrm{HSQC}$ spectrum $\left(400 \mathrm{MHz}, 101 \mathrm{MHz}, 25{ }^{\circ} \mathrm{C}, \mathrm{CD}_{2} \mathrm{Cl}_{2}\right)$ of the $1,2-$ and 2,1-insertion products from the reaction of allyl diethyl phosphonate with 1-dmso. 


\subsection{Insertion Studies of iso-Butyl Acrylate}

A NMR tube was charged with 1-dmso $(77 \mathrm{mM})$ in $\mathrm{CD}_{2} \mathrm{Cl}_{2}$ at $25{ }^{\circ} \mathrm{C}$ and 36 equivalents of iso-butyl acrylate were added. After already $10 \mathrm{~min}$ the clear solution turned yellow. After 1 hour a ${ }^{1} \mathrm{H}-{ }^{1} \mathrm{H}$ gCOSY spectrum was acquired revealing complete consumption of the Pd-Me species by iso-butyl acrylate insertion into the Pd-Me bond which is afforded by 2,1-insertion solely (green in Figure S18).

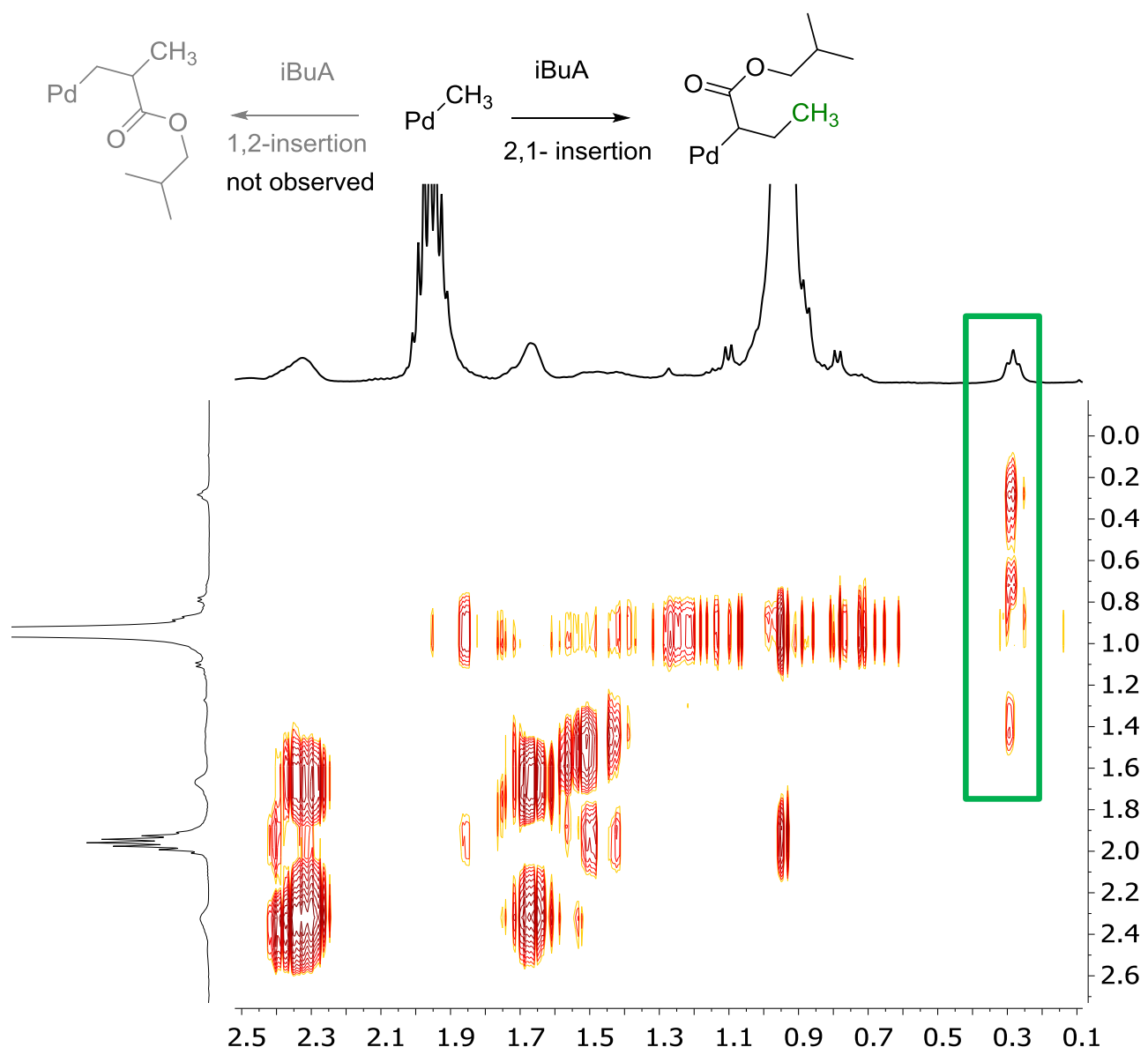

Figure S18. ${ }^{1} \mathrm{H}-{ }^{1} \mathrm{H}-\mathrm{gCOSY}$ spectrum $\left(\mathrm{CD}_{2} \mathrm{Cl}_{2}, 400 \mathrm{MHz}, 25{ }^{\circ} \mathrm{C}\right)$ for the insertion of iso-butyl acrylate (36 eq.) into the Pd-Me of 1-dmso (76 mM). 


\section{Pressure Reactor Polymerization Experiments}

\subsection{General Procedures for Co- and Terpolymerizations}

Polymerizations were carried out in a $250 \mathrm{~mL}$ stainless steel mechanically stirred (1000 rpm) pressure reactor equipped with a heating/cooling jacket supplied by a thermostat controlled by a thermocouple dipping into the polymerization mixture. A valve controlled by a pressure transducer allowed for applying and keeping up a constant ethylene pressure. Prior to a polymerization experiment, the reactor was heated under vacuum to the desired reaction temperature for $30-60$ min and then back-filled with argon.

A solution of toluene and comonomer was cannula transferred into the reactor with an argon counter stream. 3,5-di-tert-butyl-4-hydroxytoluene was added to the monomer solution as a radical inhibitor. The catalyst precursor was dissolved in $\mathrm{CH}_{2} \mathrm{Cl}_{2}(0.5 \mathrm{~mL})$ and added via a syringe to the mixture in the reactor. Optionally, the reactor was first pressurized with propylene until saturation at the desired pressure was reached. The propylene connection was then closed. Ethylene was then applied continously during the polymerization. After polymerization the reactor was rapidly vented and the reaction mixture was either precipitated and washed with $\mathrm{MeOH}(400 \mathrm{~mL})$ if polar comonomer had been applied or volatiles were evaporated in vacuo. The polymers were dried under vacuum at $50{ }^{\circ} \mathrm{C}$ for at least 48 hours.

These work up procedures should remove polar comonomers, stabilizer and possibly radically formed homopolymer of the polar monomers.

\subsection{Copolymerization of Ethylene and Propylene}

Copolymerization of ethylene with propylene was studied with the known catalyst precursors 1-dmso ${ }^{1}$ and 2-tmeda ${ }^{2}$ (Figure S19 and Table S1). While the former is highly active in homoand copolymerizations of ethylene with relatively high incorporation ratios of comonomers but affords rather low molecular weights $\left(<20000 \mathrm{~g} \mathrm{~mol}^{-1}\right)$ the latter was found to 
polymerize ethylene to high molecular weight polymer $\left(M_{n}>100000 \mathrm{~g} \mathrm{~mol}^{-1}\right)$ but discriminates comonomers like acrylates more pronouncedly resulting in low comonomer incorporation.

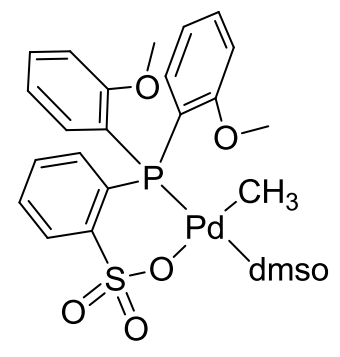

1-dmso

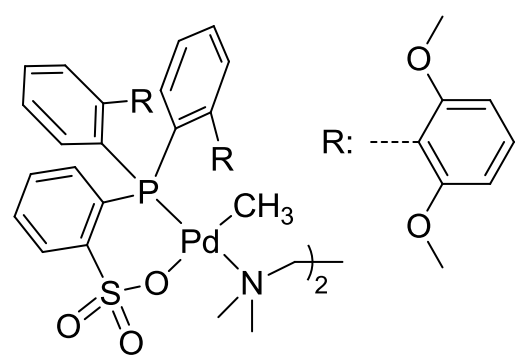

2-tmeda

Figure S19. Structure of the catalyst precursors 1-dmso and 2-tmeda.

Surprisingly, polymerization with 1-dmso at 2 bar propylene and 4 bar ethylene pressure resulted in a copolymer with only 4 methyl branches per 1000 methylene units (entry 2). This is only a negligible increase, if not even within the error, in the amount of branching compared with ethylene homopolymers obtained in the absence of propylene. However, the degrees of polymerization being lower with a $\mathrm{DP}_{\mathrm{n}}$ of 176 compared to $\mathrm{DP}_{\mathrm{n}}=348$ for polyethylene synthesized under comparable conditions. A substantial amount of methyl branches, namely 30 per 1000 methylene units, was observed at 3 bar propylene and 3 bar ethylene pressure concomitant with a further decrease in the degree of polymerization to a $\mathrm{DP}_{\mathrm{n}}$ of 92 (entry 3). Polymerization at 4.5 bar propylene and 2 bar ethylene pressure resulted in further increase in the number of methyl branches to 76 branches per 1000 methylene units and a further decrease in the polymerization degree to $\mathrm{DP}_{\mathrm{n}}=76$ (entry 4). As expected the increase in methyl branching and decrease in molecular weight strongly decreases the melting temperature and crystallinity of the polymers. 
Table S1. Copolymerization of ethylene and propylene with 1-dmso and 2-tmeda ${ }^{\mathrm{a}}$

\begin{tabular}{|c|c|c|c|c|c|c|c|c|c|}
\hline entry & $\begin{array}{c}\text { catalyst } \\
\text { precursor }\end{array}$ & $\begin{array}{c}\text { propylene } \\
\text { [bar] }^{\mathbf{b}}\end{array}$ & $\begin{array}{c}\text { ethylene } \\
\text { [bar] }^{\mathrm{c}}\end{array}$ & $\begin{array}{l}\operatorname{Pd}(\mathrm{II}) \\
{[\mu \mathrm{mol}]}\end{array}$ & $\begin{array}{c}\mathbf{t} \\
{[\mathrm{min}]}\end{array}$ & $\begin{array}{c}\text { yield } \\
\text { [g] }\end{array}$ & $\begin{array}{c}\mathrm{Me}^{\mathrm{d}, \mathrm{g}} \\
/ 1000 \mathrm{C}\end{array}$ & $\begin{array}{c}\mathrm{DP}_{\mathrm{n}} \mathrm{e}^{\mathrm{e}} \\
(\mathrm{NMR})\end{array}$ & $\begin{array}{l}T_{m} / \kappa^{f} \\
(D S C)\end{array}$ \\
\hline 1 & 1-dmso & - & 6 & 3.5 & 30 & 1.91 & 3 & 348 & $\begin{array}{l}127^{\circ} \mathrm{C} \\
182 \%\end{array}$ \\
\hline 2 & 1-dmso & 2 & 4 & 40 & 30 & 8.96 & 4 & 176 & $\begin{array}{l}110^{\circ} \mathrm{C} \\
152 \%\end{array}$ \\
\hline 3 & 1-dmso & 3 & 3 & 20 & 15 & 8.41 & 30 & 92 & $\begin{array}{l}102{ }^{\circ} \mathrm{C} \\
149 \%\end{array}$ \\
\hline 4 & 1-dmso & 4.5 & 2 & 20 & 15 & 3.07 & 76 & 37 & $\begin{array}{l}15{ }^{\circ} \mathrm{C} \\
129 \%\end{array}$ \\
\hline 5 & 2-tmeda & 4.5 & 2 & 7 & 15 & 3.47 & 15 & 360 & $\begin{array}{l}102{ }^{\circ} \mathrm{C} \\
162 \%\end{array}$ \\
\hline 6 & 1-dmso & 6 & - & 40 & 30 & 0.28 & - & ca 20 & n.d. \\
\hline 7 & 2-tmeda & 6 & - & 7 & 30 & traces & n.d. & n.d. & n.d. \\
\hline
\end{tabular}

${ }^{\mathrm{a}}$ polymerization conditions: $100 \mathrm{~mL}$ of toluene, $95^{\circ} \mathrm{C}$ reaction temperature. ${ }^{\mathrm{b}}$ initital pressure, without further feeding. ${ }^{c}$ constant pressure, through feeding of ethylene during polymerization. ${ }^{\mathrm{d}}$ determined by quantitative ${ }^{13} \mathrm{C}$ NMR spectroscopy at $130{ }^{\circ} \mathrm{C}$ in $\mathrm{C}_{2} \mathrm{D}_{2} \mathrm{Cl}_{4}$. ${ }^{\mathrm{e}}$ determined by ${ }^{1} \mathrm{H}$ NMR spectroscopy at $130{ }^{\circ} \mathrm{C}$ in $\mathrm{C}_{2} \mathrm{D}_{2} \mathrm{Cl}_{4}$ assuming that every polymer chain consists of one aliphatic and one olefinic chain end, n.d. not determined. ${ }^{f}$ determined by differential scanning calorimetry at a heating and cooling rate, respectively, of $10 \mathrm{~K} \mathrm{~min}^{-1} .{ }^{\mathrm{g}} \mathrm{It}$ should be noted that methyl branch content of polyethylene in the absence of propylene also increases slightly with the lowering of ethylene pressure.

A copolymerization under identical conditions using 2-tmeda as a catalyst precursor lead to 15 methyl branches per 1000 methylene units compared to 76 with 1-dmso and a substantially higher chain length of 360 monomer units compared to 37 with 1-dmso (entry 4 vs. entry 5). 


\subsection{Homooligomerization of Propylene}

Both catalyst precursors, 1-dmso and 2-tmeda, were employed for propylene homopolymerizations. 2-tmeda was found to be rather inactive and lead only to traces of polymer which were not further analyzed. 1-dmso, in contrast, produces a transparent oily material. NMR spectroscopy provides insights into the microstructure of the obtained polypropylene. The ratio of methylene protons to methyl protons determined by ${ }^{1} \mathrm{H}$ NMR spectroscopy was found to be 2.0:3.0 which corresponds very well to an expected value of 2:3 for a polypropylene without any 1,3-enchainments as it was observed for other late transition metal catalysts ${ }^{5}$ and also found to be possible in the polymerization of ethylene with phosphinesulfonato palladium(II) catalysts ${ }^{6,7}$. However it is not clarified for propylene if elimination and subsequent reinsertion occurs and if insertion at the less sterically hindered Catom is beneficial. The degree of polymerization, determined by the ratio of aliphatic resonances to olefinic end groups was found to be $\sim 10$. The ${ }^{13} \mathrm{C}$ NMR spectrum (Figure S21) is very complex since the resonances of the in-chain repeat units not only reflect various stereo- and regiochemistry, but are also influenced by adjacent end groups which are not negligible in an oligomer of merely 10 propylene units. Methyl branches resonating in the range of $\delta\left({ }^{13} \mathrm{C}\right) 19.4-21.5 \mathrm{ppm}$ were ascribed to consecutive 1,2-insertions of propylene (head-to-tail) and account for about $93 \%$ of all methyl branches. Methyl branch resonances at $\delta\left({ }^{13} \mathrm{C}\right) \sim 14.7 \mathrm{ppm}$ are characteristic for regio errors resulting from a $(1,2)(2,1)(1,2)$ insertion sequence (head-to-head + tail-to-tail) and represent about $7 \%$ of all methyl branch resonances. Only traces, too low in intensity for reasonable integration, at $\delta\left({ }^{13} \mathrm{C}\right) 15.7 \mathrm{ppm}$ result from $(1,2)(1,2)(2,1)(2,1)$-head-to-head sequences. ${ }^{8}$ These results are in accordance with 1,2- insertion being much faster and therefore occurring more preferably than 2,1-insertion, as observed in the preceding NMR study. 
Scheme S3. Homooligomerization of propylene with 1-dmso.

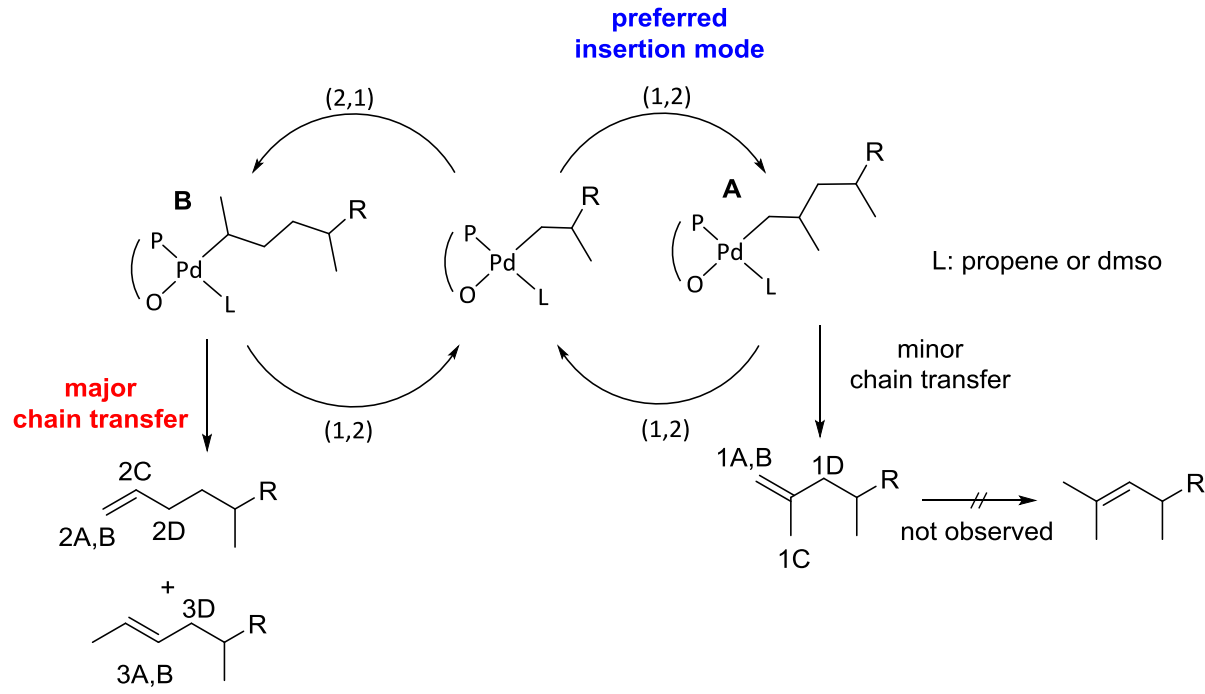

$3 A, B$
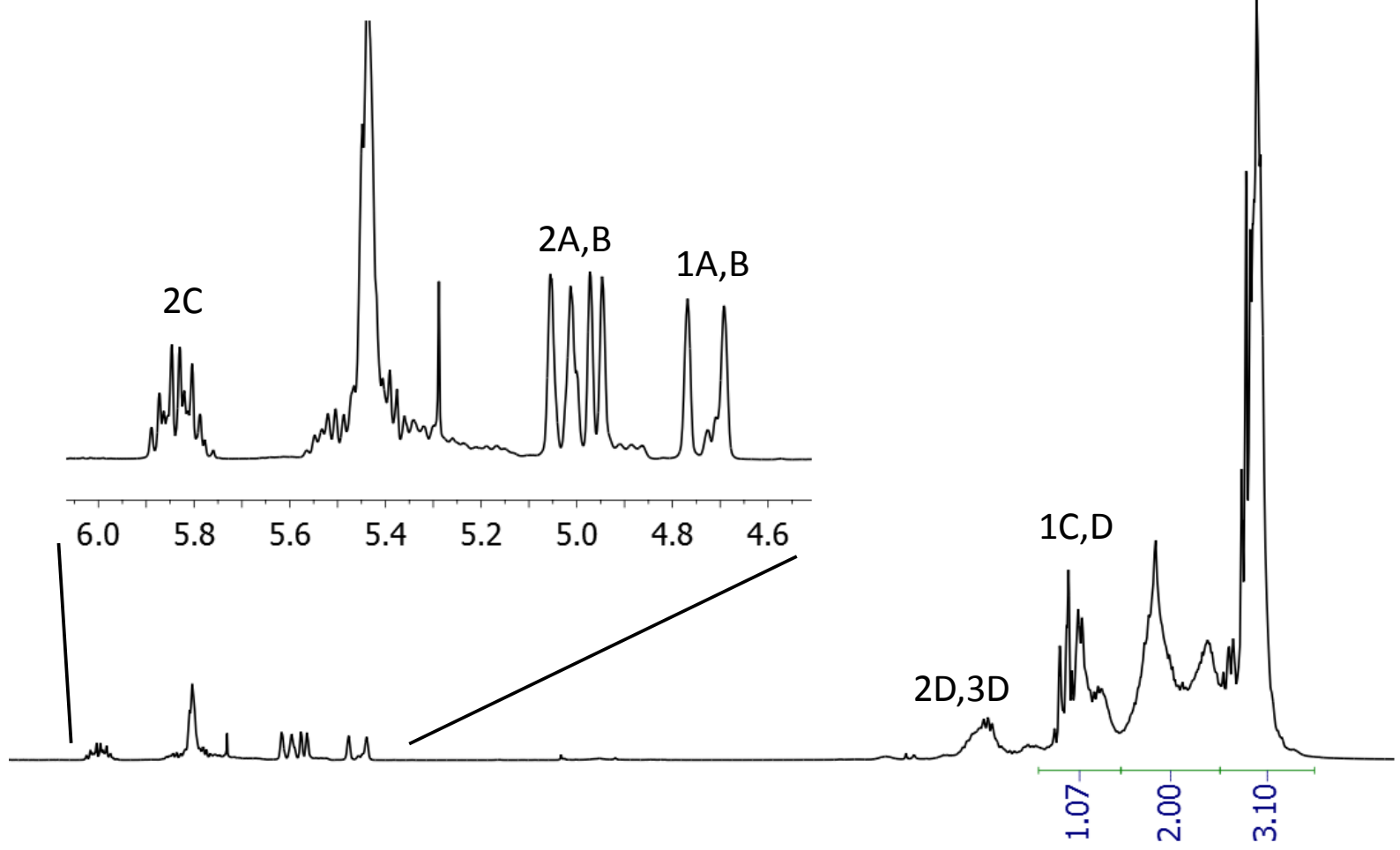

$\begin{array}{lllllllllllllll}6.0 & 5.6 & 5.2 & 4.8 & 4.4 & 4.0 & 3.6 & 3.2 & 2.8 & 2.4 & 2.0 & 1.6 & 1.2 & 0.8 & 0.4\end{array}$

Figure S20. ${ }^{1} \mathrm{H}$ NMR spectrum $\left(400 \mathrm{MHz}, 25^{\circ} \mathrm{C}, \mathrm{CDCl}_{3}\right)$ of polypropylene oligomers obtained with 1-dmso (Table S1, entry 6). 


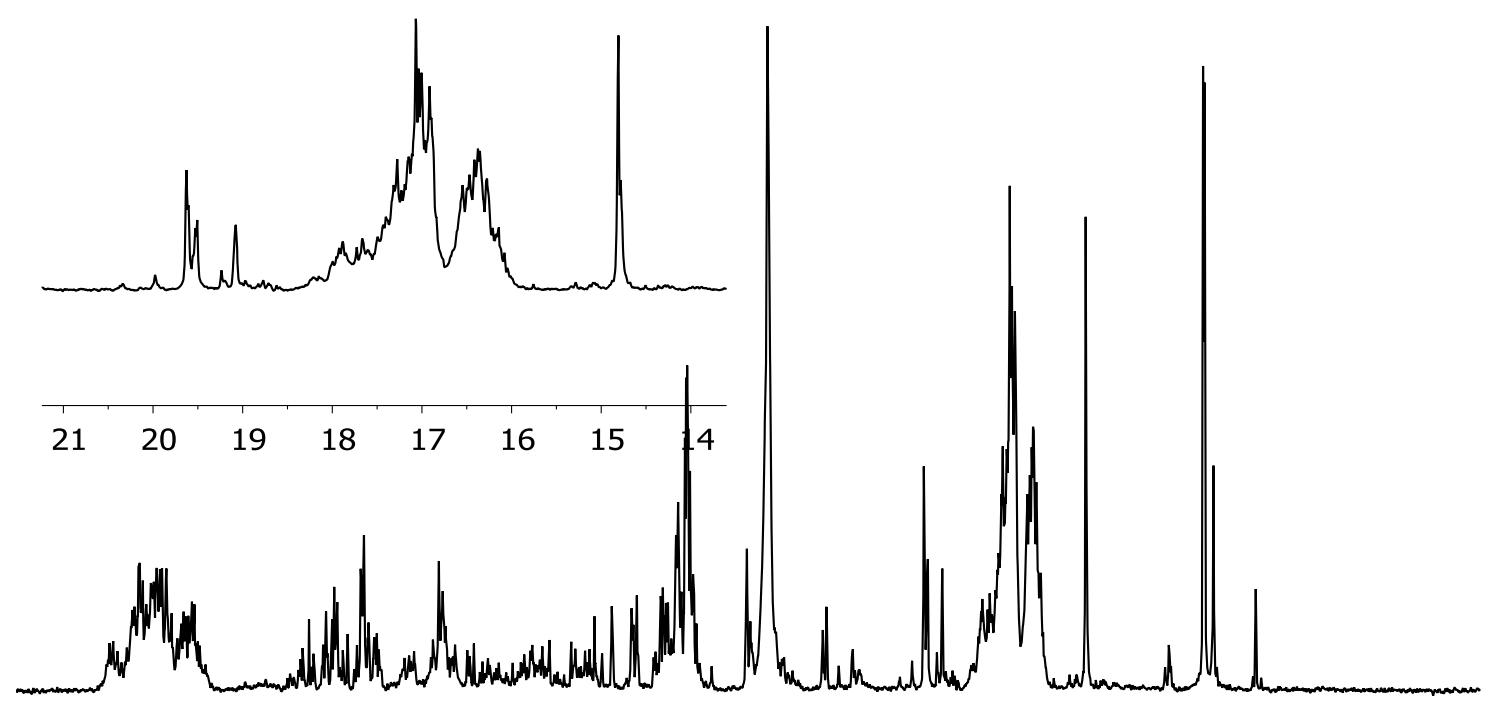

$\begin{array}{llllllllllllllllllllll}46 & 44 & 42 & 40 & 38 & 36 & 34 & 32 & 30 & 28 & 26 & 24 & 22 & 20 & 18 & 16 & 14 & 12 & 10 & 8 & 6 & 4\end{array}$

Figure S21. ${ }^{13} \mathrm{C}$ NMR spectrum (inverse gated decoupled, $101 \mathrm{MHz}, 25{ }^{\circ} \mathrm{C}, \mathrm{CDCl}_{3}$ ) of polypropylene oligomers obtained with 1-dmso (table 1, entry 6).

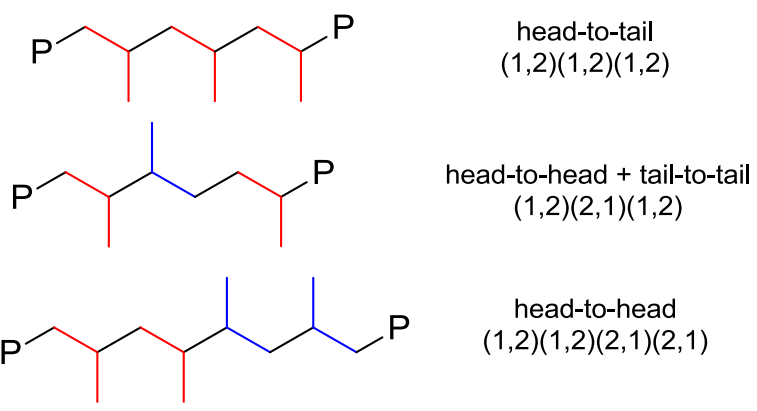

Figure S22. Regio isomers occurring in propylene oligomerization with 1-dmso.

The corresponding ${ }^{1} \mathrm{H}$ NMR spectrum (Figure S20) shows the formation of several unsaturated end groups resulting from $\beta$-hydride elimination after propylene insertion. The possible end groups based on a preceding 1,2-insertion are illustrated in Scheme S3. A consecutive 1,2-insertion, which was found to be the preferred insertion mode in NMR insertion experiments and also confirmed by ${ }^{13} \mathrm{C}$ NMR, results in the exemplified complex A 
which bears only one hydrogen in $\beta$-position, thus $\beta$-hydride elimination results exclusively in the vinylidene end group 1. Further isomerization to an internal olefin was not observed. In case of the less preferred 2,1-insertion, which is exemplified in complex B, $\beta$-hydride elimination may result in a terminal olefin 2 or an internal olefin 3. Note that terminal olefins tend to isomerize to the more stable internal olefins 3 , thus hampering the determination of the ratio of end group 2 to 3 . The ratio of vinylidene end groups 1 to terminal and internal end groups $2+3$ was found to be $1: 6$, that is chain transfer proceeds preferentially after 2,1 insertion. However it should be noted that $\beta$-hydride elimination after 2,1-insertion is statistically preferred over $\beta$-hydride elimination after 1,2 -insertion due to five $\beta$-hydrides present in the 2,1-insertion product compared to only one $\beta$-hydride in the 1,2 insertion product. Hence the origin for the low molecular weights in propylene insertion copolymerization is the strong tendency for $\beta$-hydride elimination after 2,1-insertion despite being the much less preferred insertion mode (Scheme S3).

\subsection{Terpolymerizations of Propylene, Ethylene and Polar Vinyl Monomers}

While free-radical copolymerizations of ethylene with polar vinyl monomers such as acrylates and insertion copolymerizations of ethylene, propylene and other $\alpha$-olefins by early transition metals are applied on a large industrial scale, the terpolymerization of ethylene, polar vinyl monomers and propylene has not been possible so far. This is mostly due to propylene being unreactive in radical polymerization owing to the formation of a stable allyl radical ${ }^{9}$ and polar vinyl monomers being incompatible with early transition metals. ${ }^{10}$ Therefore we investigated the terpolymerization of ethylene and propylene with polar vinyl monomers, namely methyl acrylate and acrylic acid, with the neutral phosphinesulfonato $\mathrm{Pd}(\mathrm{II})$ catalyst precursor 1dmso (Table S2). 


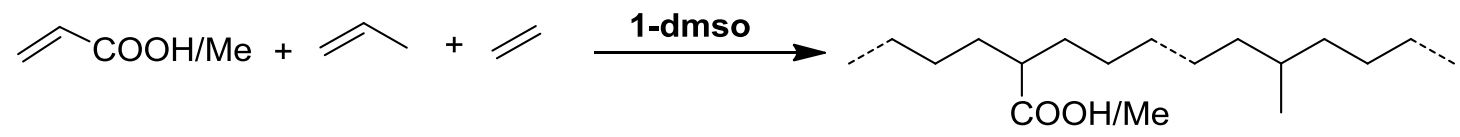

Table S2. Terpolymerization of ethylene with propylene or methyl acrylate (MA) and acrylic acid (AA), respectively, with 1-dmso.

\begin{tabular}{|c|c|c|c|c|c|c|c|c|c|}
\hline entry & $\begin{array}{c}\mathbf{E}^{\mathbf{c}} \\
{[\text { bar] }}\end{array}$ & $\begin{array}{c}\mathbf{P}^{\mathbf{b}} \\
{[\text { bar] }}\end{array}$ & $\begin{array}{l}\text { yield } \\
{[\mathrm{mg}]}\end{array}$ & $\begin{array}{l}\text { conc. AA } \\
{\left[\mathrm{mol} \mathrm{L}^{-1}\right]}\end{array}$ & $\begin{array}{l}\text { conc. MA } \\
{\left[\mathrm{mol} \mathrm{L}^{-1}\right]}\end{array}$ & $\begin{array}{l}\mathbf{A A} / \mathbf{M A}^{\mathrm{e}} \\
\text { content } \\
{[\mathrm{mol} \%]}\end{array}$ & $\begin{array}{c}\mathbf{P}^{\mathbf{e}} \\
\text { content } \\
{[\text { mol \%] }}\end{array}$ & $\begin{array}{c}\mathbf{T}_{\mathbf{m}} / \boldsymbol{\kappa}^{\mathbf{d}} \\
{\left[{ }^{\circ} \mathbf{C} / \%\right]}\end{array}$ & $\mathbf{D P}_{\mathbf{n}}{ }^{\mathrm{e}}$ \\
\hline 1 & 3 & 3 & 512 & - & 0.1 & 3.2 & 7.1 & $69^{\circ} \mathrm{C} / 46 \%$ & 122 \\
\hline 2 & 3 & 3 & 155 & - & 0.3 & 7.7 & 4.8 & $56^{\circ} \mathrm{C} / 26 \%$ & 101 \\
\hline 3 & 3 & 3 & n.p. & - & 0.6 & - & - & - & - \\
\hline 4 & 3 & 3 & 173 & 0.1 & - & 3.1 & 5.9 & $82^{\circ} \mathrm{C} / 44 \%$ & 133 \\
\hline 5 & 3 & 3 & n.p. & 0.3 & - & - & - & - & - \\
\hline
\end{tabular}

a polymerization conditions: $100 \mathrm{~mL}$ toluene; $95^{\circ} \mathrm{C}$ reaction temperature, $20 \mu \mathrm{mol} \mathbf{1 - d m s o}$, polymerization time: $15 \min ^{\mathrm{b}}$ propylene pressure was applied once at the beginning of the experiment until saturation. It should be kept in mind that during this period insertion into the catalyst precursor already takes place to some extent leading to some propylene oligomers which are removed during work up ${ }^{\mathrm{c}}$ ethylene pressure was constantly applied during polymerization, ${ }^{\mathrm{d}}$ determined by differential scanning calorimetry at a heating rate of $10 \mathrm{~K}$ $\min ^{-1}$ e determined by ${ }^{1} \mathrm{H}$ NMR spectroscopy at $130{ }^{\circ} \mathrm{C}$ in $\mathrm{C}_{2} \mathrm{D}_{2} \mathrm{Cl}_{4}$. n.p. no polymer isolable.

Due to the relatively low incorporations of propylene and polar monomer of 3 to $8 \%$ each, signals for consecutive propylene sequences are very low in intensity in ${ }^{13} \mathrm{C}$ NMR spectra (Figure S25). Polar monomer content increases with increasing comonomer concentration along with decreasing propylene content. As expected degrees of polymerization $\mathrm{DP}_{\mathrm{n}}$ as well as polymer melting points and crystallinity decrease with higher total comonomer content (Table S2, entry 1 vs. entry 2). While the yields in the copolymerizations of ethylene with propylene under given conditions are in the range of several grams similar to ethylene homopolymerization, yields are decreased considerably to only a few hundred milligrams in 
the presence of acrylic acid and methyl acrylate, respectively (cf. Entry 3 in Table S1 with Table S2). The yields are decreased with higher polar comonomer concentrations (Table S2, entry 1 vs. 2). At a concentration of $0.6 \mathrm{~mol} \mathrm{~L}^{-1}$ of methyl acrylate and already $0.3 \mathrm{~mol} \mathrm{~L}^{-1}$ of acrylic acid no polymer could be isolated not even in the evaporated methanol filtrates. This is due to significant reversible deactivation of the catalyst by $\kappa$-O-coordination of the functional group in methyl acrylate and acrylic acid, respectively, lowering its activity which is not observed for propylene. Furthermore, it could be observed that the catalytic activity was neglectable after already $15 \mathrm{~min}$ of polymerization time while under comparable polymerization conditions the catalyst stays active for mostly an hour in the presence of only methyl acrylate or acrylic acid. Since catalyst deactivation mainly occurs via reaction between a palladium alkyl species and a palladium hydride ${ }^{3}$ and the latter being formed via $\beta$-hydride elimination and subsequent chain transfer the high chain transfer tendency for propylene compared to ethylene lowers the catalyst productivity considerably under the given conditions.

Interestingly, degrees of polymerization are higher compared to the ethylene-propylene copolymers despite comparable or even higher propylene contents (cf. entry 3, Table S1 vs. entry 1 and 4, Table S2). End group analysis shows only three types of unsaturated end groups: terminal and internal olefins as well as polar monomer derived end groups. This is in accordance with the major chain transfer in propylene insertion occuring after the less favoured 2,1-insertion of propylene leading to internal and terminal olefins and not vinylidenes (cf. Scheme S3). Therefore it is not possible to distinguish between ethylene and propylene derived end groups since they furthermore tend to isomerize to internal olefins under polymerization conditions. Characterization of Polymers 


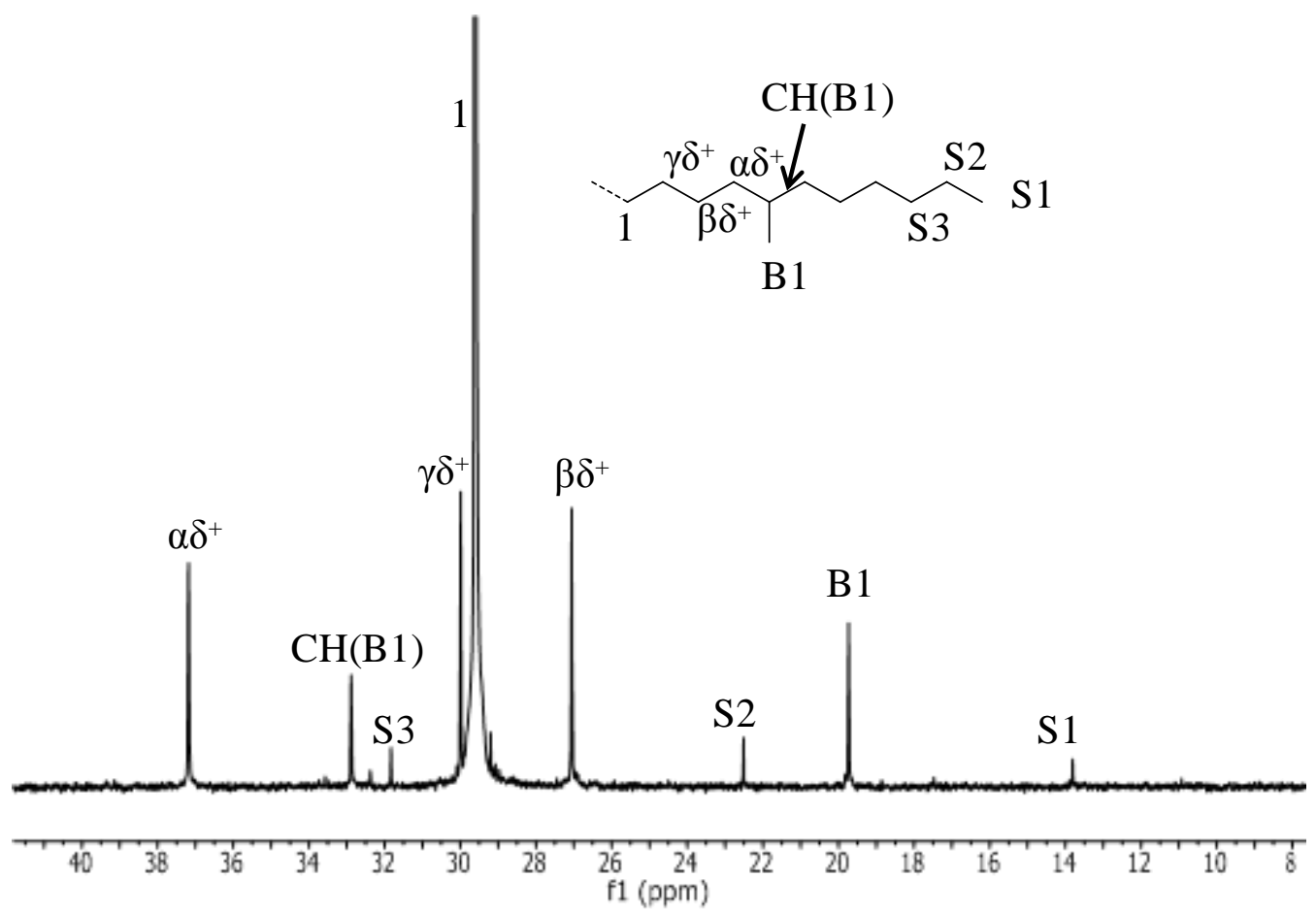

Figure S23. ${ }^{1} \mathrm{H}$ NMR spectrum $\left(\mathrm{C}_{2} \mathrm{D}_{2} \mathrm{Cl}_{4}, 130{ }^{\circ} \mathrm{C}, 400 \mathrm{MHz}\right)$ of an ethylene/propylene copolymer with $5.1 \mathrm{~mol} \%$ propylene content.

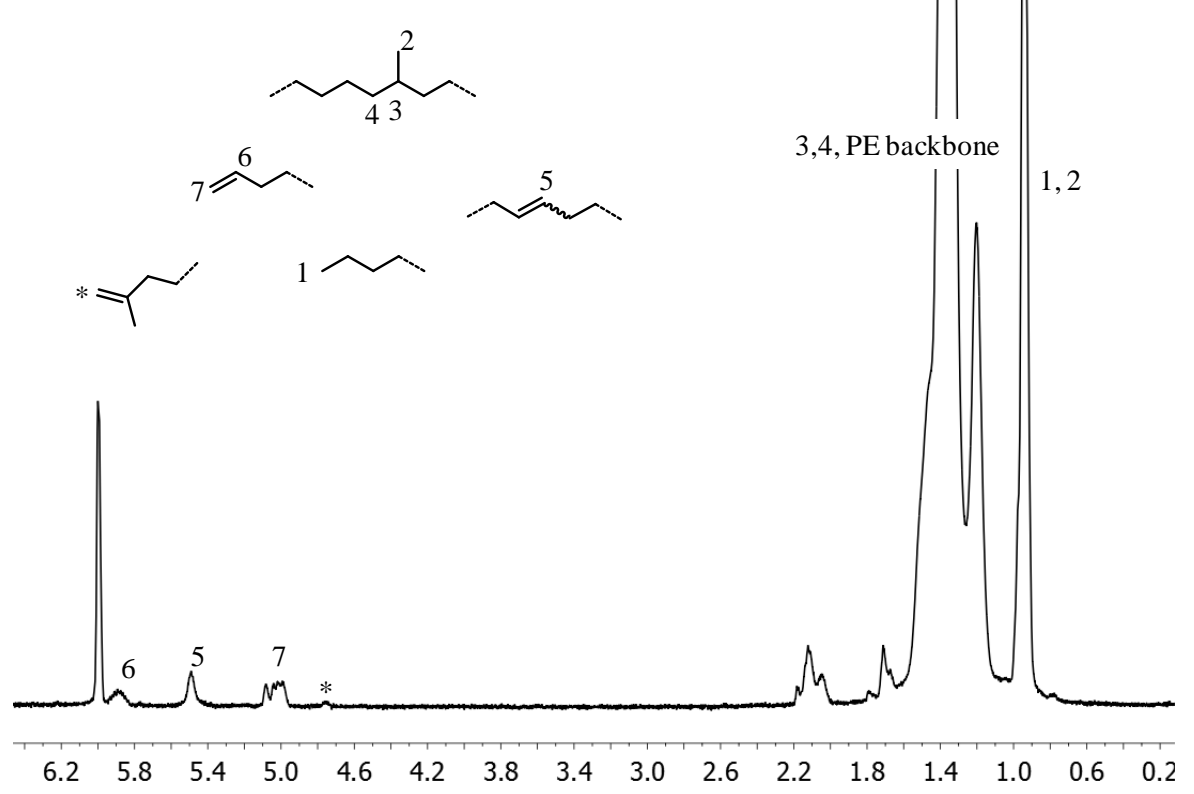


Figure S24. ${ }^{1} \mathrm{H}$ NMR spectrum $\left(\mathrm{C}_{2} \mathrm{D}_{2} \mathrm{Cl}_{4}, 130{ }^{\circ} \mathrm{C}, 400 \mathrm{MHz}\right)$ of an ethylene/propylene copolymer (signal denoted with an asterisk corresponds to a propylene-derived vinylidene end group which is too low in intensity to be reasonably integrated).

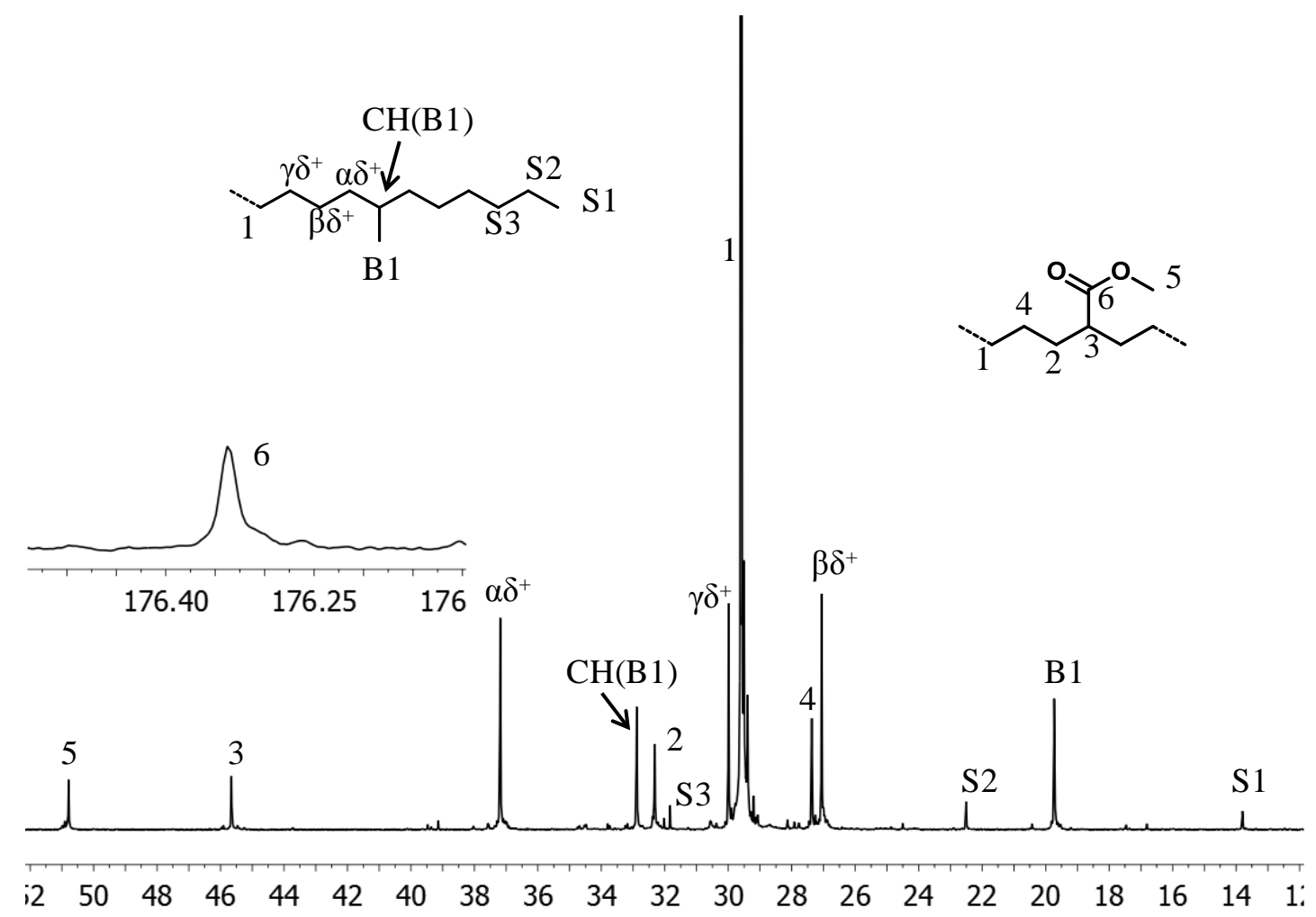

Figure S25. ${ }^{13} \mathrm{C}$ NMR spectrum (inverse gated decoupled, $\mathrm{C}_{2} \mathrm{D}_{2} \mathrm{Cl}_{4}, 130{ }^{\circ} \mathrm{C}, 101 \mathrm{MHz}$ ) of an ethylene/propylene/methyl acrylate terpolymer with $3.2 \mathrm{~mol} \%$ methyl acrylate and $7.1 \mathrm{~mol} \%$ propylene. 


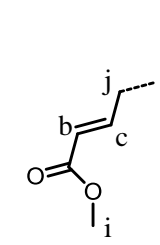<smiles>CCCCC(C)CCCC</smiles><smiles>CCCCCC</smiles><smiles>CC/C=C/C(C)C</smiles>

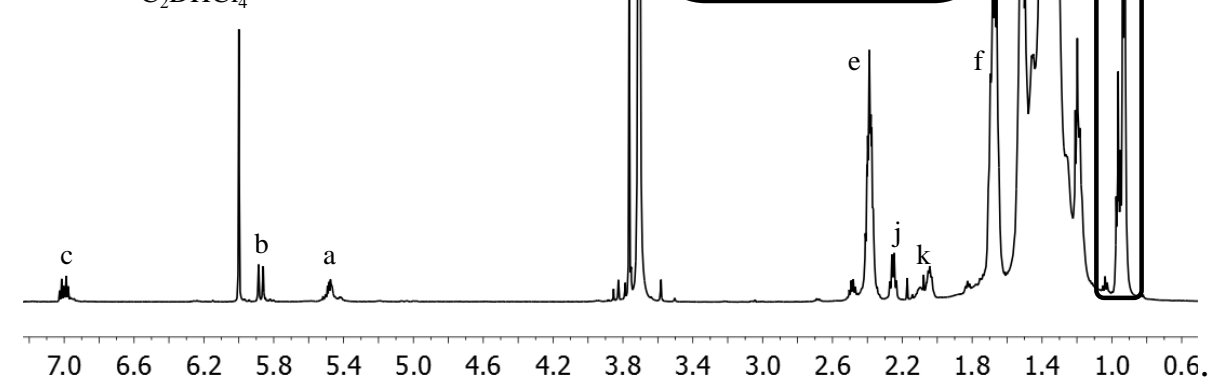

Figure S26. ${ }^{1} \mathrm{H}$ NMR spectrum $\left(\mathrm{C}_{2} \mathrm{D}_{2} \mathrm{Cl}_{4}, 130{ }^{\circ} \mathrm{C}, 400 \mathrm{MHz}\right)$ of an ethylene/propylene/methyl acrylate terpolymer.

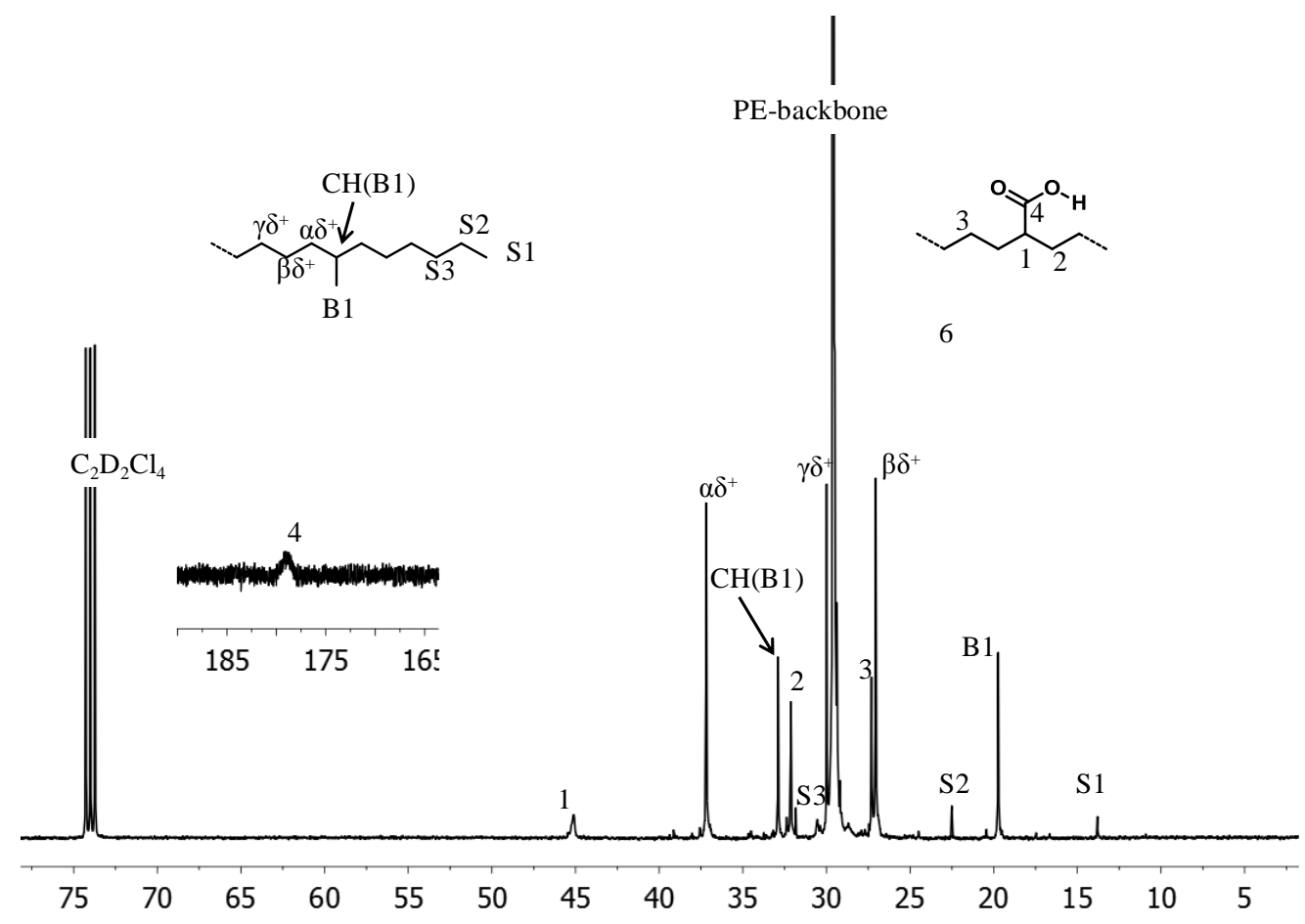

Figure S27. ${ }^{13} \mathrm{C}$ NMR spectrum (inverse gated decoupled, $\mathrm{C}_{2} \mathrm{D}_{2} \mathrm{Cl}_{4}, 130{ }^{\circ} \mathrm{C}, 101 \mathrm{MHz}$ ) of an ethylene/propylene/acrylic acid terpolymer with $3.1 \mathrm{~mol} \%$ acrylic acid and $5.9 \mathrm{~mol} \%$ propylene. 


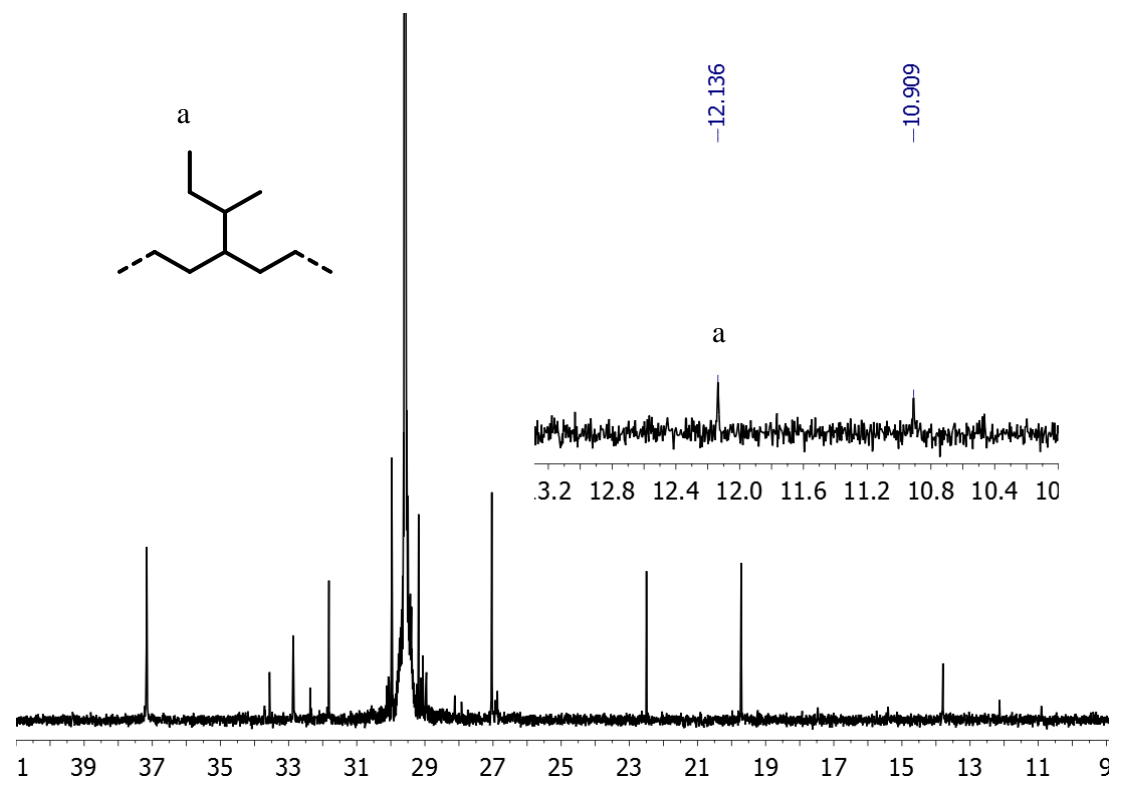

Figure S28. ${ }^{13} \mathrm{C}$ NMR spectrum $\left(\mathrm{C}_{2} \mathrm{D}_{2} \mathrm{Cl}_{4}, 130{ }^{\circ} \mathrm{C}, 101 \mathrm{MHz}\right)$ of an ethylene/3-methyl-1pentene copolymer with $0.2 \mathrm{~mol} \% 3$-methyl-1-pentene incorporation.

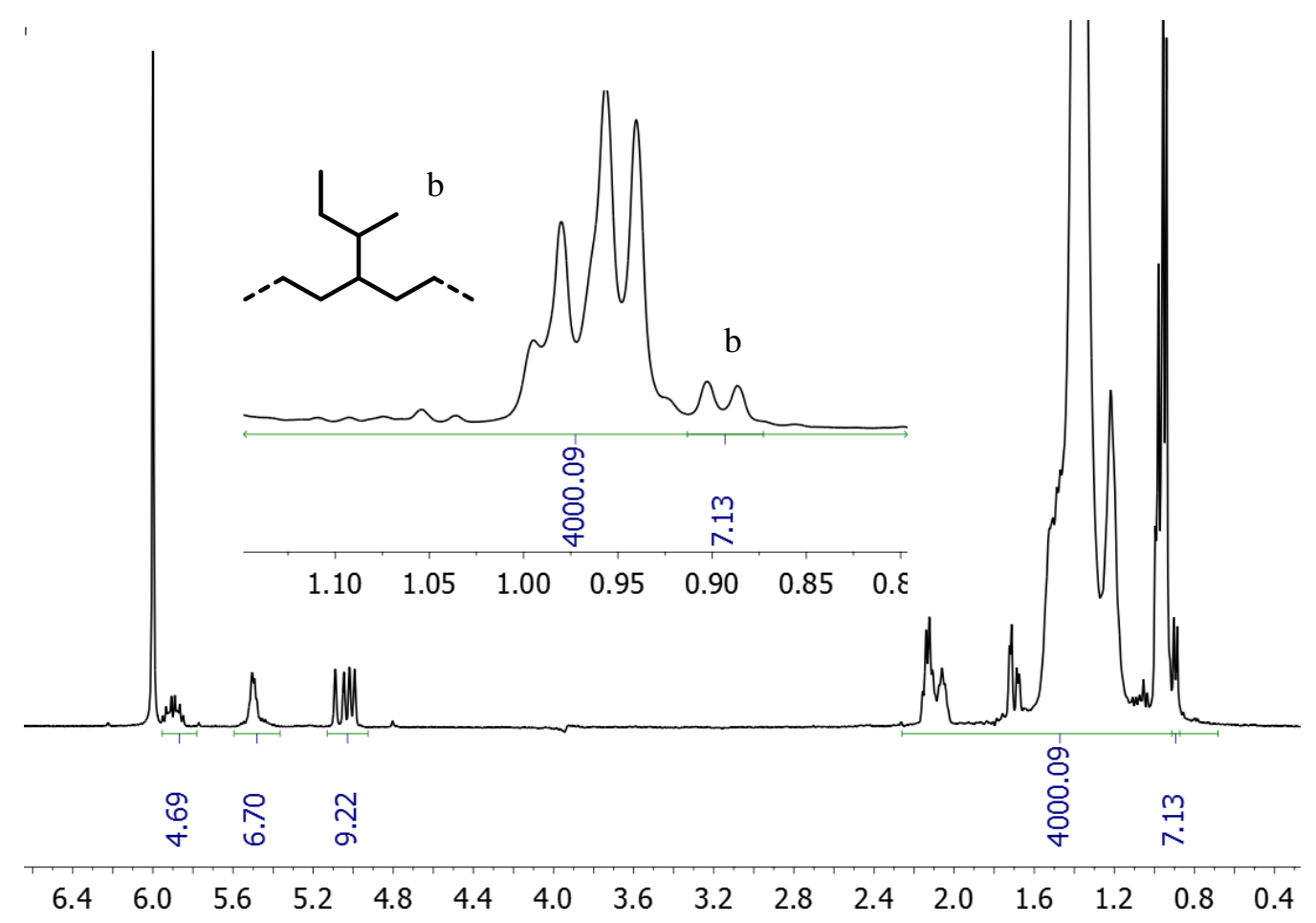

Figure S29. ${ }^{1} \mathrm{H}$ NMR spectrum $\left(\mathrm{C}_{2} \mathrm{D}_{2} \mathrm{Cl}_{4}, 130{ }^{\circ} \mathrm{C}, 400 \mathrm{MHz}\right)$ of an ethylene/3-methyl-1pentene copolymer with $0.2 \mathrm{~mol} \% 3$-methyl-1-pentene incorporation. 


\section{Determination of Gas Solubility}

The concentration of propylene in toluene at 3 bar and at $95{ }^{\circ} \mathrm{C}$ was determined by a gravimetric method. A $100 \mathrm{~mL}$ stainless steel reactor was kept at $95{ }^{\circ} \mathrm{C}$ in an oil bath and saturated with propylene until a constant mass was achieved. In order to determine the amount of propylene gas in the head space of the reactor the liquid phase was mimicked via glass beads of the same volume. The same procedure was applied to determine the solubility of ethylene in toluene at $95{ }^{\circ} \mathrm{C}$ and at 3, 5, 10 and 20 bar ethylene pressure. Measurements were repeated 3 times for each data point.

Table S3. Gas solubility determination results of ethylene in toluene at $95{ }^{\circ} \mathrm{C}$ and 3 bar.

\begin{tabular}{|c|c|c|c|}
\hline experiment & $\mathbf{m}_{1}[\mathrm{~g}]$ & $\mathbf{m}_{2}[\mathbf{g}]$ & $\mathbf{m}_{2}-\mathbf{m}_{1}[\mathrm{~g}]$ \\
\hline 1 & 3805.75 & 3806.00 & 0.25 \\
\hline 2 & 3806.20 & 3806.45 & 0.25 \\
\hline \multirow[t]{2}{*}{3} & 3806.45 & 3806.70 & 0.25 \\
\hline & & & $0.25( \pm 0.00)$ \\
\hline \multicolumn{4}{|c|}{$\mathrm{m}_{1}-$ mass of $40 \mathrm{~mL}$ toluene + reactor + magnetic stirring bar } \\
\hline \multicolumn{4}{|c|}{$\mathrm{m}_{2}-$ mass of $40 \mathrm{~mL}$ toluene + reactor + magnetic stirring bar + ethylene equilibrated at $95^{\circ} \mathrm{C}$} \\
\hline \multicolumn{4}{|l|}{ and 20 bar } \\
\hline \multicolumn{4}{|c|}{$\mathrm{m}_{2}-\mathrm{m}_{1}-$ ethylene in reactor head space and liquid phase } \\
\hline experiment & $\mathbf{m}_{3}[\mathrm{~g}]$ & $m_{4}[g]$ & $m_{4}-m_{3}[g]$ \\
\hline
\end{tabular}




\begin{tabular}{llcc}
\hline $\mathbf{1}$ & 3871.55 & 3871.70 & 0.15 \\
$\mathbf{2}$ & 3873.65 & 3873.75 & 0.10 \\
$\mathbf{3}$ & 3873.45 & 3873.55 & 0.10 \\
\hline
\end{tabular}

$0.12( \pm 0.03)$

$\mathrm{m}_{3}$ - mass of reactor and glass beads which correspond to $40 \mathrm{~mL}$ fluid

$\mathrm{m}_{4}$ - mass of reactor and glass beads which correspond to $40 \mathrm{~mL}$ fluid + ethylene equilibrated at $95{ }^{\circ} \mathrm{C}$ and 20 bar

$\mathrm{m}_{4}-\mathrm{m}_{3}$ - ethylene gas in head space of reactor

ethylene in liquid phase $: \mathrm{m}_{2}-\mathrm{m}_{1}-\left(\mathrm{m}_{4}-\mathrm{m}_{3}\right)=0.130 \mathrm{~g}( \pm 0.03 \mathrm{~g}) \rightarrow 0.0046 \mathrm{~mol}$ in 0.041 toluene

$\rightarrow[\text { ethylene }]_{95^{\circ}} \mathrm{C}, 3 \mathrm{bar}$, toluene $=0.12 \mathrm{~mol} / \mathrm{L}( \pm 0.029 \mathrm{~mol} / \mathrm{L})\left(\mathrm{x}_{\text {ethylene }}=0.012\right)$

Table S4. Gas solubility determination results of ethylene in toluene at $95{ }^{\circ} \mathrm{C}$ and 5 bar.

\begin{tabular}{cccc}
\hline experiment & $\mathbf{m}_{\mathbf{1}}[\mathbf{g}]$ & $\mathbf{m}_{\mathbf{2}}[\mathbf{g}]$ & $\mathbf{m}_{\mathbf{2}}-\mathbf{m}_{\mathbf{1}}[\mathbf{g}]$ \\
\hline $\mathbf{1}$ & 3805.75 & 3806.20 & 0.40 \\
$\mathbf{2}$ & 3806.20 & 3806.70 & 0.50 \\
$\mathbf{3}$ & 3806.45 & 3806.95 & 0.50 \\
\hline
\end{tabular}

$0.47( \pm 0.05)$

$\mathrm{m}_{1}$ - mass of $40 \mathrm{~mL}$ toluene + reactor + magnetic stirring bar

$\mathrm{m}_{2}$ - mass of $40 \mathrm{~mL}$ toluene + reactor + magnetic stirring bar + ethylene equilibrated at $95{ }^{\circ} \mathrm{C}$ and 20 bar

$\mathrm{m}_{2}-\mathrm{m}_{1}-$ ethylene in reactor head space and liquid phase 


\begin{tabular}{cccc}
\hline experiment & $\mathbf{m}_{\mathbf{3}}[\mathbf{g}]$ & $\mathbf{m}_{\mathbf{4}}[\mathbf{g}]$ & $\mathbf{m}_{\mathbf{4}}-\mathbf{m}_{\mathbf{3}}[\mathbf{g}]$ \\
\hline $\mathbf{1}$ & 3871.55 & 3871.80 & 0.20 \\
$\mathbf{3}$ & 3873.65 & 3873.85 & 0.20 \\
& 3873.45 & 3873.65 & 0.20 \\
\hline
\end{tabular}

$\mathrm{m}_{3}$ - mass of reactor and glass beads which correspond to $40 \mathrm{~mL}$ fluid

$\mathrm{m}_{4}$ - mass of reactor and glass beads which correspond to $40 \mathrm{~mL}$ fluid + ethylene equilibrated at $95{ }^{\circ} \mathrm{C}$ and 20 bar

$\mathrm{m}_{4}-\mathrm{m}_{3}$ - ethylene gas in head space of reactor

ethylene in liquid phase $: \mathrm{m}_{2}-\mathrm{m}_{1}-\left(\mathrm{m}_{4}-\mathrm{m}_{3}\right)=0.270 \mathrm{~g}( \pm 0.05) \rightarrow 0.0096 \mathrm{~mol}$ in 0.041 toluene

$\rightarrow[\text { ethylene }]_{95^{\circ}} \mathrm{C}, 5 \mathrm{bar}$, toluene $=0.24 \mathrm{~mol} / \mathrm{L}( \pm 0.098 \mathrm{~mol} / \mathrm{L})\left(\mathrm{x}_{\text {ethylene }}=0.024\right)$

Table S5. Gas solubility determination results of ethylene in toluene at $95{ }^{\circ} \mathrm{C}$ and $10 \mathrm{bar}$.

\begin{tabular}{cccc}
\hline experiment & $\mathbf{m}_{\mathbf{1}}[\mathbf{g}]$ & $\mathbf{m}_{\mathbf{2}}[\mathbf{g}]$ & $\mathbf{m}_{\mathbf{2}}-\mathbf{m}_{\mathbf{1}}[\mathbf{g}]$ \\
\hline $\mathbf{1}$ & 3805.60 & 3806.75 & 1.15 \\
$\mathbf{2}$ & 3806.20 & 3807.40 & 1.20 \\
\hline & 3806.85 & 3808.10 & 1.25 \\
\hline
\end{tabular}

$\mathrm{m}_{1}$ - mass of $40 \mathrm{~mL}$ toluene + reactor + magnetic stirring bar

$\mathrm{m}_{2}$ - mass of $40 \mathrm{~mL}$ toluene + reactor + magnetic stirring bar + ethylene equilibrated at $95{ }^{\circ} \mathrm{C}$ and 20 bar

$\mathrm{m}_{2}-\mathrm{m}_{1}-$ ethylene in reactor head space and liquid phase 


\begin{tabular}{cccc}
\hline experiment & $\mathbf{m}_{\mathbf{3}}[\mathbf{g}]$ & $\mathbf{m}_{\mathbf{4}}[\mathbf{g}]$ & $\mathbf{m}_{\mathbf{4}}-\mathbf{m}_{\mathbf{3}}[\mathbf{g}]$ \\
\hline $\mathbf{1}$ & 3871.35 & 3871.80 & 0.45 \\
$\mathbf{3}$ & 3873.65 & 3874.05 & 0.40 \\
& 3873.45 & 3873.95 & 0.50 \\
\hline
\end{tabular}

$\mathrm{m}_{3}$ - mass of reactor and glass beads which correspond to $40 \mathrm{~mL}$ fluid

$\mathrm{m}_{4}$ - mass of reactor and glass beads which correspond to $40 \mathrm{~mL}$ fluid + ethylene saturated at $95^{\circ} \mathrm{C}$ and 20 bar

$\mathrm{m}_{4}-\mathrm{m}_{3}$ - ethylene gas in head space of reactor

ethylene in liquid phase $: \mathrm{m}_{2}-\mathrm{m}_{1}-\left(\mathrm{m}_{4}-\mathrm{m}_{3}\right)=0.750 \mathrm{~g}( \pm 0.13 \mathrm{~g}) \rightarrow 0.027 \mathrm{~mol}$ in 0.041 toluene

$\rightarrow[\text { ethylene }]_{95^{\circ}} \mathrm{C}$, 5bar, toluene $=0.67 \mathrm{~mol} / \mathrm{L}( \pm 0.20 \mathrm{~mol} / \mathrm{L})\left(\mathrm{x}_{\text {ethylene }}=0.067\right)$

Table S6. Gas solubility determination results of ethylene in toluene at $95{ }^{\circ} \mathrm{C}$ and $20 \mathrm{bar}$.

\begin{tabular}{cccc}
\hline experiment & $\mathbf{m}_{\mathbf{1}}[\mathbf{g}]$ & $\mathbf{m}_{\mathbf{2}}[\mathbf{g}]$ & $\mathbf{m}_{\mathbf{2}}-\mathbf{m}_{\mathbf{1}}[\mathbf{g}]$ \\
\hline $\mathbf{1}$ & 3806.20 & 3808.70 & 2.50 \\
$\mathbf{2}$ & 3806.45 & 3809.00 & 2.55 \\
$\mathbf{3}$ & 3806.85 & 3809.35 & 2.50 \\
\hline
\end{tabular}

$2.52( \pm 0.03)$

$\mathrm{m}_{1}$ - mass of $40 \mathrm{~mL}$ toluene + reactor + magnetic stirring bar

$\mathrm{m}_{2}$ - mass of $40 \mathrm{~mL}$ toluene + reactor + magnetic stirring bar + ethylene equilibrated at $95{ }^{\circ} \mathrm{C}$ and 20 bar 
$\mathrm{m}_{2}-\mathrm{m}_{1}-$ ethylene in reactor head space and liquid phase

\begin{tabular}{cccc}
\hline experiment & $\mathbf{m}_{\mathbf{3}}[\mathbf{g}]$ & $\mathbf{m}_{\mathbf{4}}[\mathbf{g}]$ & $\mathbf{m}_{\mathbf{4}}-\mathbf{m}_{\mathbf{3}}[\mathbf{g}]$ \\
\hline $\mathbf{1}$ & 3871.35 & 3872.20 & 0.85 \\
$\mathbf{2}$ & 3873.65 & 3874.50 & 0.85 \\
$\mathbf{3}$ & 3873.45 & 3874.40 & 0.95 \\
\hline
\end{tabular}

$0.88( \pm 0.06)$

$\mathrm{m}_{3}$ - mass of reactor and glass beads which correspond to $40 \mathrm{~mL}$ fluid

$\mathrm{m}_{4}$ - mass of reactor and glass beads which correspond to $40 \mathrm{~mL}$ fluid + ethylene equilibrated at $95{ }^{\circ} \mathrm{C}$ and 20 bar

$\mathrm{m}_{4}-\mathrm{m}_{3}$ - ethylene gas in head space of reactor

ethylene in liquid phase $: \mathrm{m}_{2}-\mathrm{m}_{1}-\left(\mathrm{m}_{4}-\mathrm{m}_{3}\right)=1.64 \mathrm{~g}( \pm 0.09 \mathrm{~g}) \rightarrow 0.059 \mathrm{~mol}$ in 0.041 toluene

$\rightarrow[\text { ethylene }]_{95^{\circ}} \mathrm{C}, 5 \mathrm{bar}$, toluene $=1.43 \mathrm{~mol} / \mathrm{L}( \pm 0.08 \mathrm{~mol} / \mathrm{L})\left(\mathrm{x}_{\text {ethylene }}=0.147\right)$ 


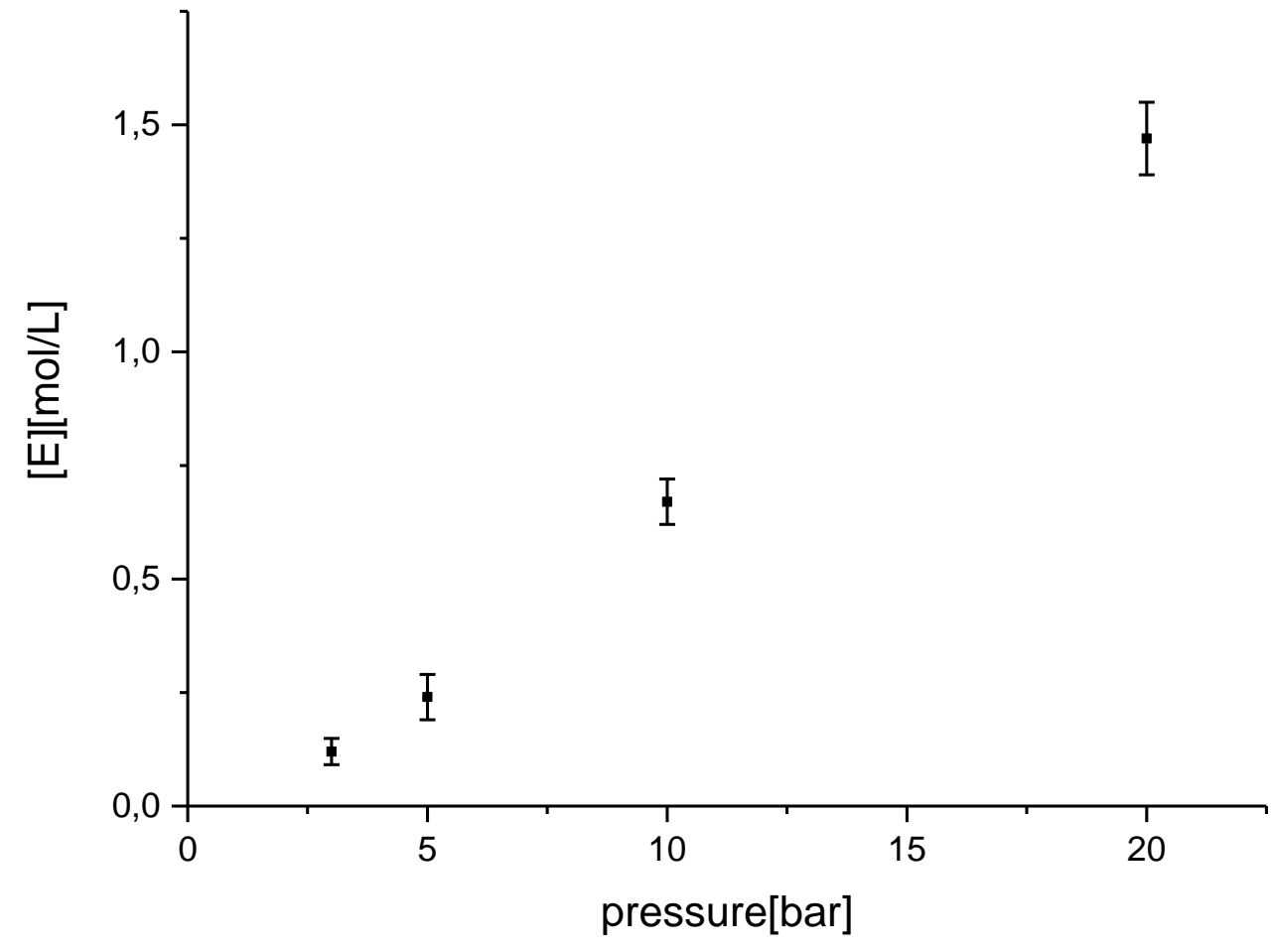

Figure S30. Solubility of ethylene in toluene at $95{ }^{\circ} \mathrm{C}$ determined gravimetrically. Error bars represent the standard deviation. 
Table S7. Gas solubility determination results of propylene in toluene at $95{ }^{\circ} \mathrm{C}$ and $3 \mathrm{bar}$.

\begin{tabular}{cccc}
\hline experiment & $\mathbf{m}_{\mathbf{1}}[\mathbf{g}]$ & $\mathbf{m}_{\mathbf{2}}[\mathbf{g}]$ & $\mathbf{m}_{\mathbf{2}}-\mathbf{m}_{\mathbf{1}}[\mathbf{g}]$ \\
\hline $\mathbf{1}$ & 3805.20 & 3806.30 & 1.10 \\
$\mathbf{2}$ & 3805.15 & 3806.30 & 1.15 \\
$\mathbf{3}$ & 3805.05 & 3806.20 & 1.15 \\
\hline
\end{tabular}

$\mathrm{m}_{1}$ - mass of $40 \mathrm{~mL}$ toluene + reactor + magnetic stirring bar

$\mathrm{m}_{2}$ - mass of $40 \mathrm{~mL}$ toluene + reactor + magnetic stirring bar + propylene equilibrated at 95 ${ }^{\circ} \mathrm{C}$ and 3 bar $\mathrm{m}_{2}-\mathrm{m}_{1}-$ propylene in reactor head space and liquid phase

\begin{tabular}{cccc}
\hline experiment & $\mathbf{m}_{\mathbf{3}}[\mathbf{g}]$ & $\mathbf{m}_{\mathbf{4}}[\mathbf{g}]$ & $\mathbf{m}_{\mathbf{4}}-\mathbf{m}_{\mathbf{3}}[\mathbf{g}]$ \\
\hline $\mathbf{1}$ & 3872.60 & 3872.80 & 0.20 \\
$\mathbf{3}$ & 3872.50 & 3872.70 & 0.20 \\
& 3872.50 & 3872.70 & 0.20 \\
\hline
\end{tabular}

$\mathrm{m}_{3}$ - mass of reactor and glass beads which correspond to $40 \mathrm{~mL}$ fluid

$\mathrm{m}_{4}$ - mass of reactor and glass beads which correspond to $40 \mathrm{~mL}$ fluid + propylene equilibrated at $95{ }^{\circ} \mathrm{C}$ and 3 bar

$\mathrm{m}_{4}-\mathrm{m}_{3}-$ propylene gas in head space of reactor

propylene in liquid phase $: \mathrm{m}_{2}-\mathrm{m}_{1}-\left(\mathrm{m}_{4}-\mathrm{m}_{3}\right)=0.93 \mathrm{~g}( \pm 0.03 \mathrm{~g}) \rightarrow 0.022 \mathrm{~mol}$ in 0.041 toluene

$\rightarrow[\text { propylene }]_{95^{\circ}} \mathrm{C}, 3 \mathrm{bar}$, toluene $=0.55 \mathrm{~mol} / \mathrm{L}( \pm 0.02 \mathrm{~mol} / \mathrm{L})\left(\mathrm{x}_{\text {propylene }}=0.055\right)$ 


\section{Determination of Reactivity Ratios}

Table S8. Reactivity of selected polar and apolar vinyl monomers (comonomer - CM) in insertion copolymerization with ethylene with $\mathbf{1 - L}$ at $95{ }^{\circ} \mathrm{C}$ in toluene and 3-20 bar ethylene pressure.

\begin{tabular}{|c|c|c|c|c|c|c|c|c|c|c|c|c|}
\hline Copo & $\begin{array}{l}\mathbf{p}(\mathbf{E}) \\
{[\text { bar] }}\end{array}$ & $\begin{array}{c}\text { p(propene }) \\
\text { [bar] }\end{array}$ & $\begin{array}{c}{[\mathrm{E}]^{\mathrm{a}}} \\
{[\mathrm{mol} / \mathrm{L}]}\end{array}$ & $\begin{array}{c}\text { [1-olefin] }^{\mathrm{a}} \\
{[\mathrm{mol} / \mathrm{L}]}\end{array}$ & $\begin{array}{c}{[\mathrm{CM}]} \\
{[\mathrm{mol} / \mathrm{L}]}\end{array}$ & $\begin{array}{c}\text { Polymer } \\
\text { Yield } \\
\text { [g] }\end{array}$ & $\underset{\mathbf{E}^{\mathbf{b}}}{\mathbf{m o l} \%}$ & $\begin{array}{c}\text { mol\% } \\
\mathbf{C M}^{\mathbf{b}}\end{array}$ & $\begin{array}{c}\text { mol\% } \\
\text { 1-olefin }\end{array}$ & $\begin{array}{c}\text { Incorp. } \\
\text { ratio } \\
\text { E:CM } \\
\end{array}$ & $\begin{array}{c}\text { Reactivity } \\
\text { ratio } \mathbf{r}_{\mathrm{E}} \\
\mathrm{E}: \mathrm{CM} \mathbf{M}^{\mathrm{b}, \mathrm{h}}\end{array}$ & $\begin{array}{c}\text { Comonomer } \\
\text { consumption } \\
(\mathrm{g} / \%)\end{array}$ \\
\hline $\mathbf{E} / \mathbf{M A}^{\mathbf{f}}$ & 5 & - & 0.24 & - & 0.60 & 0.30 & 87 & 13 & - & $7: 1$ & $18: 1$ & $0.100 / 2$ \\
\hline E/MA & 5 & - & 0.24 & - & 0.60 & 1.50 & 88 & 12 & - & $7: 1$ & $18: 1$ & $0.443 / 8.5$ \\
\hline average & & & & & & & & & & & $18: 1( \pm 0)$ & \\
\hline \multirow[t]{3}{*}{$\mathbf{E} / \mathbf{n B u A} \mathbf{A}^{\mathrm{c}}$} & 5 & - & 0.24 & - & 0.30 & 2.00 & 93.4 & 6.6 & - & $14: 1$ & $18: 1$ & $0.488 / 25$ \\
\hline & 5 & - & 0.24 & - & 0.60 & 1.33 & 88.9 & 11.1 & - & $8: 1$ & $20: 1$ & $0.483 / 13$ \\
\hline & 5 & - & 0.24 & - & 0.90 & 0.95 & 82.9 & 17.1 & - & $5: 1$ & $19: 1$ & $0.461 / 8$ \\
\hline average & & & & & & & & & & & $19: 1( \pm 1)$ & \\
\hline \multirow[t]{3}{*}{$\mathbf{E} / \mathbf{i B u A}^{\mathrm{c}}$} & 5 & - & 0.24 & - & 0.30 & 2.24 & 94.4 & 5.6 & - & $17: 1$ & $21: 1$ & $0.477 / 25$ \\
\hline & 5 & - & 0.24 & - & 0.60 & 1.65 & 89.7 & 10.3 & - & $9: 1$ & $23: 1$ & $0.568 / 15$ \\
\hline & 5 & - & 0.24 & - & 0.90 & 1.02 & 84.6 & 15.4 & - & $6: 1$ & $23: 1$ & $0.463 / 8$ \\
\hline average & & & & & & & & & & & $22: 1( \pm 1)$ & \\
\hline \multirow[t]{3}{*}{$\mathbf{E} / \mathbf{t B u A}^{\mathrm{c}}$} & 5 & - & 0.24 & - & 0.30 & 2.11 & 96.5 & 3.5 & - & $28: 1$ & $35: 1$ & $0.300 / 16$ \\
\hline & 5 & - & 0.24 & - & 0.60 & 1.10 & 94.0 & 6.0 & - & $16: 1$ & $40: 1$ & $0.248 / 6$ \\
\hline & 5 & - & 0.24 & - & 0.90 & 0.80 & 91.0 & 9.0 & - & $10: 1$ & $38: 1$ & $0.249 / 4$ \\
\hline average & & & & - & & & & & & & $38: 1( \pm 2)$ & \\
\hline $\mathbf{E} \mathbf{E H A}^{\mathrm{c}}$ & 5 & - & 0.24 & - & 0.30 & 2.35 & 95.2 & 4.8 & - & $20: 1$ & $25: 1$ & $0.585 / 21$ \\
\hline E/FurA ${ }^{c}$ & 5 & - & 0.24 & - & 0.30 & 0.13 & 93.9 & 6.1 & - & $15: 1$ & $19: 1$ & $0.034 / 1.5$ \\
\hline \multirow[t]{3}{*}{$\mathbf{E} / \mathbf{G A}^{\mathrm{c}}$} & 5 & - & 0.24 & - & 0.50 & 0.76 & 88.7 & 11.3 & - & $8: 1$ & $17: 1$ & $0.280 / 8.6$ \\
\hline & 5 & - & 0.24 & - & 0.25 & 1.35 & 93.6 & 6.4 & - & $15: 1$ & $16: 1$ & $0.325 / 20$ \\
\hline & 5 & - & 0.24 & - & 0.1 & 3.01 & 97.9 & 2.1 & - & $47: 1$ & $20: 1$ & $0.274 / 42$ \\
\hline average & & & & & & & & & & & $18: 1( \pm 2)$ & \\
\hline \multirow[t]{2}{*}{ E/HEA $^{c}$} & 5 & - & 0.24 & - & 0.50 & 0.25 & 89.6 & 10.4 & - & $8.6: 1$ & $18: 1$ & $0.081 / 2.8$ \\
\hline & 5 & - & 0.24 & - & 0.75 & 0.04 & 86.8 & 13.2 & - & $7: 1$ & $22: 1$ & $0.016 /<<1$ \\
\hline average & & & & & & & & & & & $20: 1( \pm 3)$ & \\
\hline
\end{tabular}




\begin{tabular}{|c|c|c|c|c|c|c|c|c|c|c|c|c|}
\hline E/GlycA ${ }^{c}$ & 5 & - & 0.24 & - & 0.60 & 0.21 & 88.6 & 11.4 & - & $8: 1$ & $20: 1$ & $0.078 / 2$ \\
\hline & 5 & - & 0.24 & - & 0.10 & 0.91 & 97.9 & 2.1 & - & $47: 1$ & $20: 1$ & $0.081 / 13$ \\
\hline average & & & & & & & & & & & $20: 1( \pm 0)$ & \\
\hline \multirow[t]{3}{*}{ E/MEEA ${ }^{\mathrm{c}}$} & 5 & - & 0.24 & - & 0.10 & 3.57 & 98.0 & 2.0 & - & $49: 1$ & $20: 1$ & $0.403 / 46$ \\
\hline & 5 & - & 0.24 & - & 0.25 & 1.30 & 94.1 & 5.9 & - & $16: 1$ & $17: 1$ & $0.364 / 17$ \\
\hline & 5 & - & 0.24 & - & 0.50 & 0.61 & 90.0 & 10.0 & - & $9: 1$ & $19: 1$ & $0.250 / 5.7$ \\
\hline average & & & & & & & & & & & $19: 1( \pm 2)$ & \\
\hline \multirow[t]{2}{*}{$\begin{array}{c}\mathrm{E} / \\
\mathrm{OOPCA}^{\mathrm{c}}\end{array}$} & 5 & - & 0.24 & - & 0.10 & 4.31 & 98.1 & 1.9 & - & $52: 1$ & $22: 1$ & $1.00-0.9 / 37-46$ \\
\hline & 5 & - & 0.24 & - & 0.25 & 3.57 & 94.7 & 5.3 & - & $18: 1$ & $19: 1$ & $\begin{array}{c}1.68-1.75 / 28- \\
32 \\
\end{array}$ \\
\hline average & & & & & & & & & & & $21: 1( \pm 2)$ & \\
\hline \multirow[t]{3}{*}{$\begin{array}{c}\text { E/ } \\
\text { TMSPA }^{\text {c }}\end{array}$} & 5 & - & 0.24 & - & 0.25 & 1.64 & 95.8 & 4.2 & - & $21: 1$ & $22: 1$ & $0.440 / 15$ \\
\hline & 5 & - & 0.24 & - & 0.50 & 0.94 & 92.7 & 7.3 & - & $13: 1$ & $27: 1$ & $0.373 / 6$ \\
\hline & 5 & - & 0.24 & - & 0.75 & 0.61 & 87.1 & 12.9 & - & $7: 1$ & 22:1 & $0.337 / 4$ \\
\hline average & & & & & & & & & & & $24: 1( \pm 3)$ & \\
\hline \multirow[t]{3}{*}{$\mathbf{E} / \mathrm{CEA}^{\mathrm{c}}$} & 5 & - & 0.24 & - & 0.10 & 0.40 & 97.8 & 3.2 & - & $31: 1$ & $13: 1$ & $0.051 / 8.2$ \\
\hline & 5 & - & 0.24 & - & 0.200 & 0.10 & 96.8 & 6.2 & - & $16: 1$ & $13: 1$ & $0.023 / 2$ \\
\hline & 5 & - & 0.24 & - & 0.3 & 0.06 & 92 & 8.0 & - & $12: 1$ & $15: 1$ & $0.017 / 0.9$ \\
\hline average & & & & & & & & & & & $14: 1( \pm 1)$ & \\
\hline \multirow[t]{3}{*}{ E/VDP ${ }^{c}$} & 5 & - & 0.24 & - & 0.40 & 0.24 & 98.4 & 1.6 & - & $62: 1$ & 103:1 & $0.021 / 0.6$ \\
\hline & 5 & - & 0.24 & - & 0.30 & 0.55 & 98.5 & 1.5 & - & $66: 1$ & $83: 1$ & $0.045 / 1.8$ \\
\hline & 5 & - & 0.24 & - & 0.20 & 0.87 & 98.8 & 1.2 & - & $82: 1$ & $68: 1$ & $0.058 / 3.5$ \\
\hline average & & & & & & & & & & & $85: 1( \pm 17)$ & \\
\hline \multirow[t]{3}{*}{$\mathbf{E} / \mathrm{VPA}^{\mathrm{c}}$} & 5 & - & 0.24 & - & 0.50 & 0.52 & 96.8 & 3.2 & - & $30: 1$ & $62: 1$ & $0.059 / 2.2$ \\
\hline & 5 & - & 0.24 & - & 0.30 & 0.23 & 98.0 & 2.0 & - & $49: 1$ & $62: 1$ & $0.017 / 1.0$ \\
\hline & 5 & - & 0.24 & - & 0.10 & 0.66 & 99.5 & 0.5 & - & 199:1 & $83: 1$ & $0.019 / 3.5$ \\
\hline average & & & & & & & & & & & $69: 1( \pm 12)$ & \\
\hline E/AIDP ${ }^{c}$ & 5 & - & 0.24 & - & 0.10 & 0.59 & 99.6 & 0.4 & - & $250: 1$ & 104:1 & $0.015 / 1.7$ \\
\hline E/AIDP ${ }^{c}$ & 5 & - & 0.24 & - & 0.30 & 0.23 & 98.8 & 1.2 & - & $82: 1$ & 103:1 & $0.016 / 0.6$ \\
\hline average & & & & & & & & & & & $104: 1( \pm 1)$ & \\
\hline
\end{tabular}




\begin{tabular}{|c|c|c|c|c|c|c|c|c|c|c|c|c|}
\hline E/AA & 10 & - & 0.67 & - & 0.60 & 0.320 & 94.6 & 5.4 & - & $18: 1$ & $16: 1$ & $0.040 / 0.9$ \\
\hline E/AA & 20 & - & 1.43 & - & 1.20 & 0.650 & 94.4 & 5.6 & - & $17: 1$ & $14: 1$ & $0.086 / 1.0$ \\
\hline E/AA & 5 & - & 0.24 & - & 0.30 & 0.353 & 92.6 & 7.4 & - & $13: 1$ & $16: 1$ & $0.060 / 2.8$ \\
\hline average & & & & & & & & & & & $15: 1( \pm 1)$ & \\
\hline $\mathbf{E} / \mathbf{P}$ & 3 & 3 & 0.12 & 0.55 & - & 8.41 & 93.6 & - & 6.4 & $15: 1$ & $69: 1$ & $0.782 / 34$ \\
\hline E/P/MA & 3 & 3 & 0.12 & 0.55 & 0.10 & 0.51 & 89.7 & 3.2 & 7.1 & $\begin{array}{c}28: 1: 2 \\
\text { E:MA:P }\end{array}$ & $\begin{array}{c}\text { 64:3:1 } \\
\text { E:MA:P }\end{array}$ & $\begin{array}{c}0.052(\mathrm{P}) / 2 \\
0.047(\mathrm{MA}) / 6\end{array}$ \\
\hline E/P/AA & 3 & 3 & 0.12 & 0.55 & 0.10 & 0.17 & 91.0 & 3.1 & 5.9 & $\begin{array}{c}28: 1: 2 \\
\text { E:AA:P }\end{array}$ & $\begin{array}{c}64: 3: 1 \\
\text { E:AA:P }\end{array}$ & $\begin{array}{c}0.014(\mathrm{P}) / 0.6 \\
0.076(\mathrm{AA}) / 10\end{array}$ \\
\hline E/AIAc & 5 & - & 0.24 & - & 0.30 & 0.032 & 98.5 & 1.5 & - & $66: 1$ & $83: 1$ & $0.0017 /<<1$ \\
\hline E/AlAc & 5 & - & 0.24 & - & 0.10 & 0.076 & 99.5 & 0.5 & - & 199:1 & $83: 1$ & $0.0013 / 0.1$ \\
\hline E/AlAc & 5 & - & 0.24 & - & 0.050 & 0.149 & 99.7 & 0.3 & - & $332: 1$ & $70: 1$ & $0.0016 / 0.3$ \\
\hline average & & & & & & & & & & & $79: 1( \pm 7)$ & \\
\hline $\mathbf{E} \mathbf{A I S A}^{\mathrm{e}}$ & 5 & - & 0.24 & - & 1.0 & 0.270 & 96.3 & 3.7 & - & $26: 1$ & $108: 1$ & $0.043 / 3.1$ \\
\hline E/3M1P & 20 & - & 1.43 & 0.40 & - & 9.45 & 99.8 & - & 0.2 & 499:1 & 140:1 & $0.057 / 1.7$ \\
\hline \multirow[t]{3}{*}{ E/MVS ${ }^{d}$} & 5 & - & 0.24 & - & 0.60 & 0.54 & 95.2 & 4.8 & - & $20: 1$ & $50: 1$ & $0.114 / 4.5$ \\
\hline & 5 & - & 0.24 & - & 1.1 & 0.33 & 92.8 & 7.2 & - & $12: 1$ & $55: 1$ & $0.086 / 1.8$ \\
\hline & 5 & - & 0.24 & - & 1.2 & 0.06 & 93.2 & 6.8 & - & $14: 1$ & $70: 1$ & $0.013 / 0.2$ \\
\hline average & & & & & & & & & & & $58: 1( \pm 10)$ & \\
\hline$E / P S^{d}$ & 5 & - & 0.24 & - & 1.0 & 0.26 & 95.0 & 5.0 & - & $19: 1$ & $79: 1$ & $0.062 / 0.9$ \\
\hline \multirow[t]{2}{*}{ E/DMAA } & 20 & - & 1.43 & - & 0.22 & 1.40 & 99.72 & 0.28 & - & $356: 1$ & $55: 1$ & $0.014 / 0.6$ \\
\hline & 10 & - & 0.67 & - & 0.20 & 0.568 & 99.36 & 0.64 & - & 155:1 & $46: 1$ & $0.012 / 0.6$ \\
\hline average & & & & & & & & & & & $51: 1( \pm 6)$ & \\
\hline $\mathbf{E} / \mathbf{A N}^{\mathbf{c}}$ & 5 & - & 0.24 & - & 0.1 & 0.070 & 97.4 & 2.6 & - & $37: 1$ & $15: 1$ & $0.0034 / 1.2$ \\
\hline E/EVE & 5 & - & 0.24 & - & 0.6 & 0.503 & 99.6 & 0.4 & - & $249: 1$ & $622: 1$ & $0.005 / 0.1$ \\
\hline E/EVE & 5 & - & 0.24 & - & 1.0 & 0.293 & 99.3 & 0.7 & - & $142: 1$ & $592: 1$ & $0.005 /<<1$ \\
\hline E/EVE & 5 & - & 0.24 & - & 1.5 & 0.203 & 98.4 & 1.6 & - & $62: 1$ & $388: 1$ & $0.008 /<<1$ \\
\hline average & & & & & & & & & & & $\begin{array}{l}534: 1 \\
( \pm 127)\end{array}$ & \\
\hline $\mathbf{E} / \mathbf{N}$ & 5 & - & 0.24 & - & 0.1 & 12.01 & 97.8 & 2.1 & - & $47: 1$ & $20: 1$ & $0.805 / 86$ \\
\hline $\mathbf{E} / \mathbf{N}^{\mathrm{f}}$ & 5 & - & 0.24 & - & 0.1 & 4.73 & 93.3 & 6.7 & - & $14: 1$ & $6: 1$ & $0.919 / 98$ \\
\hline
\end{tabular}




\begin{tabular}{|c|c|c|c|c|c|c|c|c|c|c|c|c|}
\hline $\mathbf{E} / \mathbf{N}$ & 5 & - & 0.24 & - & 0.31 & 7.71 & 82.7 & 17.3 & - & $4.8: 1$ & $6: 1$ & $3.18 />100$ \\
\hline E/N & 5 & - & 0.24 & - & 0.58 & 6.44 & 69.6 & 30.4 & - & $2.3: 1$ & $6: 1$ & $3.83 / 70$ \\
\hline $\mathbf{E} / \mathbf{N}$ & 5 & - & 0.24 & - & 1.1 & 18.42 & 65.5 & 34.5 & - & $1.9: 1$ & $9: 1$ & $11.8 />100$ \\
\hline E/VA & 5 & - & 0.24 & - & 0.2 & 0.097 & 99.8 & 0.2 & - & $500: 1$ & $417: 1$ & $0.0005 /<<1$ \\
\hline E/VA & 5 & - & 0.24 & - & 0.3 & 0.030 & 99.7 & 0.3 & - & $332: 1$ & $415: 1$ & $0.0003 /<<1$ \\
\hline average & & & & & & & & & - & & $416: 1( \pm 1)$ & \\
\hline E/VPS ${ }^{c}$ & 5 & - & 0.24 & - & 0.1 & 1.31 & 99.0 & 1.0 & - & 99:1 & $41: 1$ & $0.081 / 8.8$ \\
\hline E/VPS ${ }^{\mathrm{e}}$ & 5 & - & 0.24 & - & 0.3 & 0.174 & 96.2 & 3.8 & - & $25: 1$ & $31: 1$ & $0.036 / 1.6$ \\
\hline average & & & & & & & & & & & $36: 1( \pm 7)$ & \\
\hline E/VNeoS ${ }^{c}$ & 5 & - & 0.24 & - & 0.3 & 1.49 & 97.1 & 2.9 & - & $33: 1$ & $41: 1$ & $0.238 / 8.9$ \\
\hline
\end{tabular}

${ }^{\mathrm{a}}$ concentration in neat toluene at $95{ }^{\circ} \mathrm{C} \quad \mathrm{b}$ in-chain incorporation (also includes unsaturated chain ends) vs. initiating saturated chain end of comonomer is taken into account. The comonomer incorporations and reactivity ratios determined thereof are given for the pure in-chain incorporation. The in-chain incorporations of the comonomers were determined from either inverse gated decoupled ${ }^{13} \mathrm{C} N M R$ spectra or, if possible, also from ${ }^{1} \mathrm{H}$ NMR spectra from the resonances reported in literature: $\mathrm{MA}^{11}, n \mathrm{BuA}^{11}, i \mathrm{BuA}^{11}, t \mathrm{BuA}^{11}, \mathrm{EHA}^{12}, \mathrm{FurA}^{13}, \mathrm{GA}^{13}, \mathrm{HEA}^{13}$, GlycA $^{12}, \mathrm{MEEA}^{13}, \mathrm{OOPCA}^{13}, \mathrm{TMSPA}^{12}, \mathrm{CEA}^{13}, \mathrm{VDP}^{4}, \mathrm{VPA}^{4}, \mathrm{AlDP}^{13}, \mathrm{AA}^{14}, \mathrm{AlAc}^{15}, \mathrm{AlSA}^{13}, 3 \mathrm{M} 1 \mathrm{P}^{16}, \mathrm{MVS}^{17}, \mathrm{PVS}^{17}, \mathrm{DMAA}^{18}, \mathrm{AN}^{19}, \mathrm{EVE}^{20}$, $\mathrm{N}^{21}, \mathrm{VA}^{22}, \mathrm{VPS}^{13}, \mathrm{VNeoS}^{13} .{ }^{\mathrm{c}} 50 \mathrm{~mL}$ total volume. ${ }^{\mathrm{d}} 40 \mathrm{~mL}$ total volume. ${ }^{\mathrm{e}} 10 \mathrm{ml}$ total volume. ${ }^{\mathrm{f}} 10 \mathrm{~min}$ polymerization time. ${ }^{\mathrm{g}}$ incorporation ratio $(\mathrm{E}: \mathrm{CM})=[\mathrm{E}]_{\mathrm{x}, \mathrm{polym}} /[\mathrm{CM}]_{\mathrm{x}, \text { polym }} \cdot{ }^{\mathrm{h}}$ Standard deviation is given in brackets.

Abbreviations: ethylene (E), methyl acrylate (MA), $n$-butyl acrylate ( $\boldsymbol{n B u A})$, iso-butyl acrylate (iBuA), tert-butyl acrylate $(\boldsymbol{t} \mathbf{B u A})$, 2-ethylhexyl acrylate (EHA), furfuryl acrylate (FurA), glycol acrylate (GA), hydroxyethyl acrylate (HEA), glycidyl acrylate (GlyA), 2-(2-methoxyethoxy)ethyl acrylate (MEEA), 2- 2,5,8,11,14,17,20,23-octaoxapentacosan-25-yl acrylate (glycol acrylate with 8-9 glycol units) (OOPCA), 3(trimethoxysilyl)propyl acrylate (TMSPA), 2-cyanoethyl acrylate (nitrile acrylate) (CEA), vinyl diethyl phosphonate (VDP), vinyl phosphonic acid 
(VPA), allyl diethyl phosphonate (AIDP), acrylic acid (AA), propylene (P), allyl acetate (AlAc), allyl succinyl anhydride (AISA), 3-methyl-1pentene (3M1P), methyl vinyl sulfone (MVS), phenyl vinyl sulfone (PVS), N,N-dimethyl acrylamide (DMAA), acrylonitrile (AN), ethyl vinyl ether (EVE), norbornene (N), vinyl acetate (VA), vinyl phenyl sulfonate (VPS), vinyl neopentyl sulfonate (VneoS), comonomer (CM). 


\section{Determination of Reactivity Ratios $\mathbf{r}_{\mathrm{A}}$ for Selected Vinyl Monomers via Fineman-}

\section{$\operatorname{Ross}^{23}$}

To probe wether $r_{A}$ values determined according to Table S8 reasonably describe insertion copolymerizations of ethylene with 1-dmso, Fineman-Ross plots were also determined for selected vinyl monomers (allyl acetate, acrylic acid, tert-butyl acrylate, iso-butyl acrylate and $n$-butyl acrylate).

The plots were determined according to the following equation with $\mathrm{R}=[\mathrm{A}]_{\mathrm{x}, \mathrm{polym}} /[\mathrm{B}]_{\mathrm{x}, \text { polymer }}$ and $\mathrm{C}=[\mathrm{B}]_{0} /[\mathrm{A}]_{0}$ which are reasonable approximations at the low conversions of the comonomers and continuous ethylene flow applied.

$$
\frac{C(R-1)}{R}=r_{A} \frac{C^{2}}{R}-r_{B}
$$

$r_{A}$ and $r_{B}$ are determined as gradients and y-intercepts of the linear plots, respectively. Note that $r_{B}$ values determined are not very meaningful due to low incorporations of the comonomers and corresponding low values of $r_{B}$. Deviations of $r_{A}$ determined according to Table S8 from $r_{\mathrm{A}}$ determined by Fineman-Ross-Plots are reasonable and trends for different comonomers (exemplified by the acrylates) are indicative. 


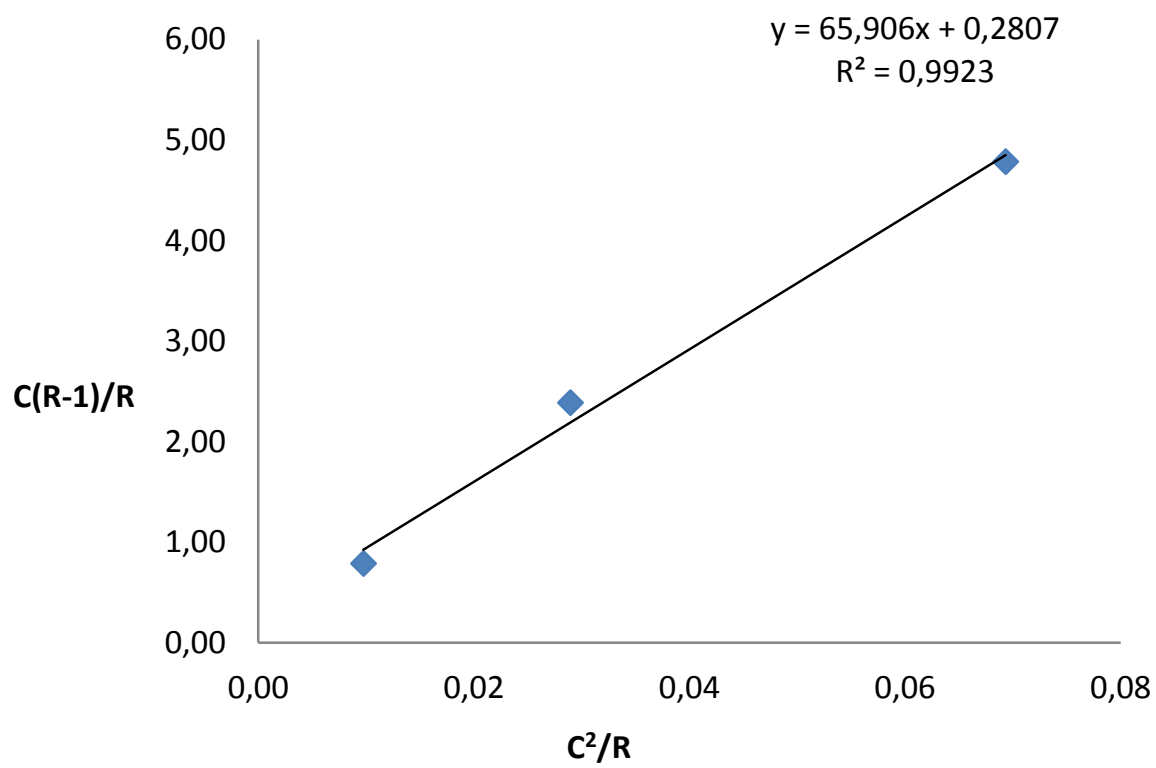

Figure S31. Fineman-Ross plot for ethylene allyl acetate copolymerizations.

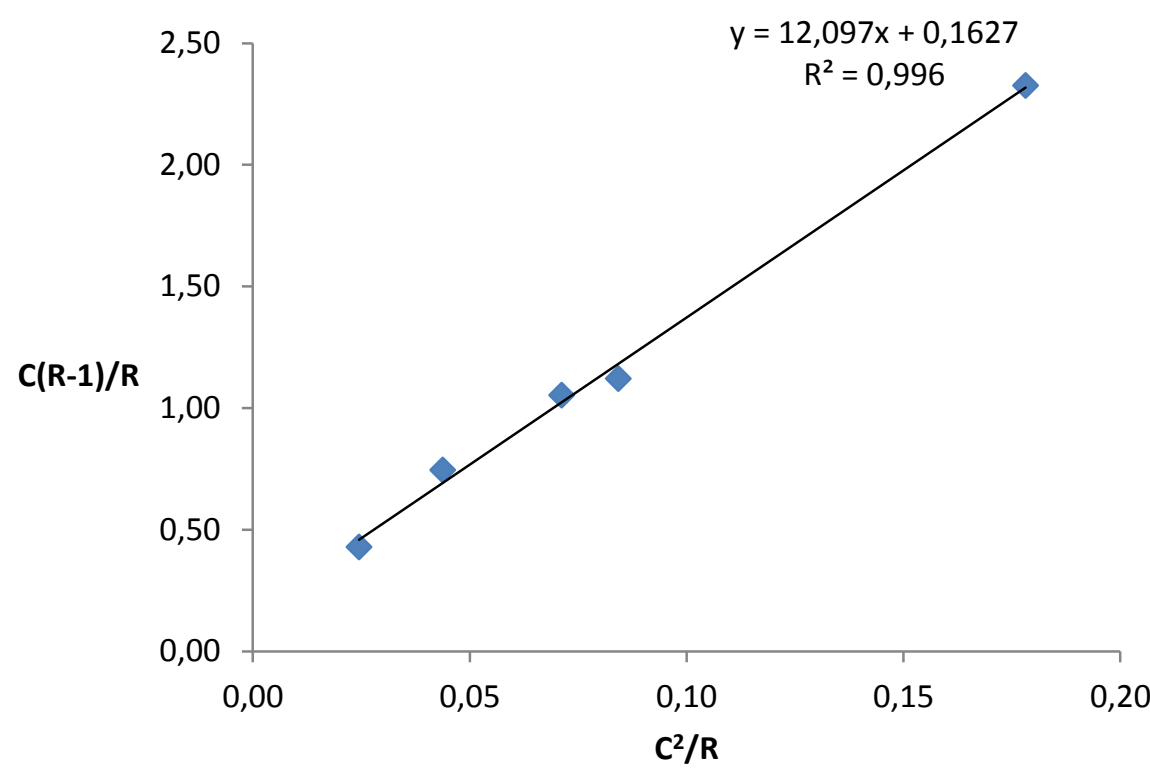

Figure S32. Fineman-Ross plot for ethylene acrylic acid copolymerizations. 


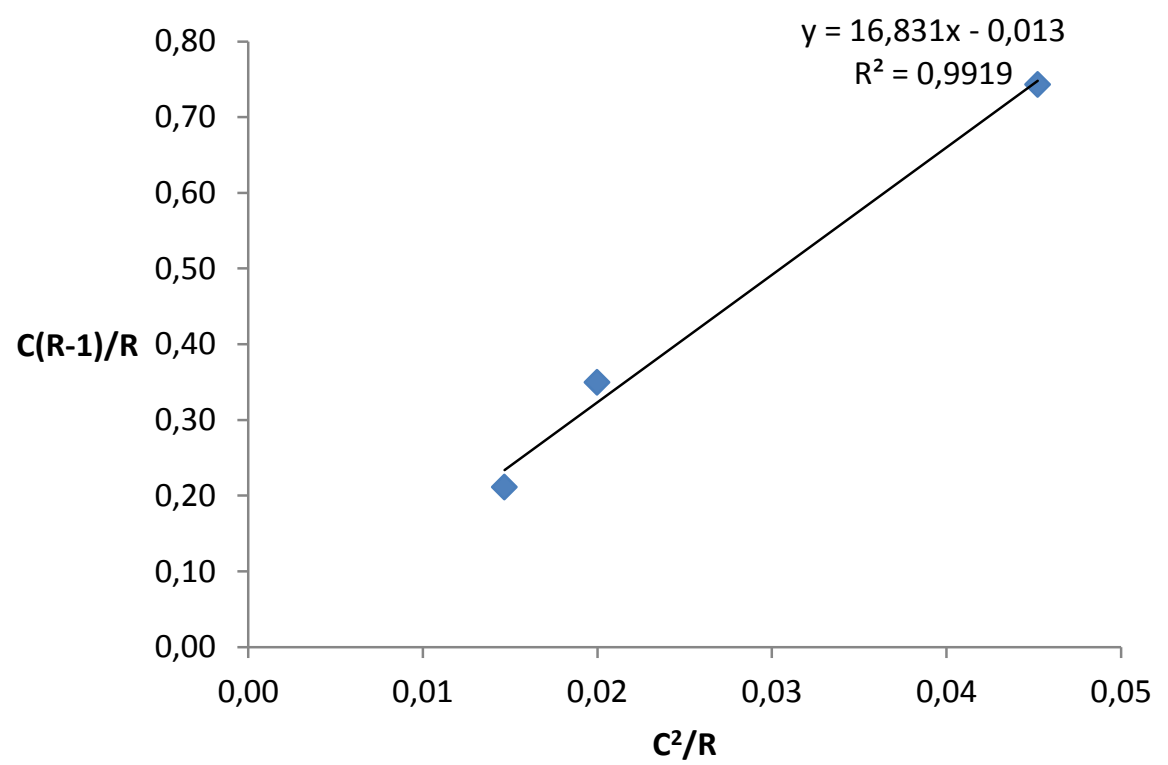

Figure S33. Fineman-Ross plot for ethylene $n$-butyl acrylate copolymerizations.

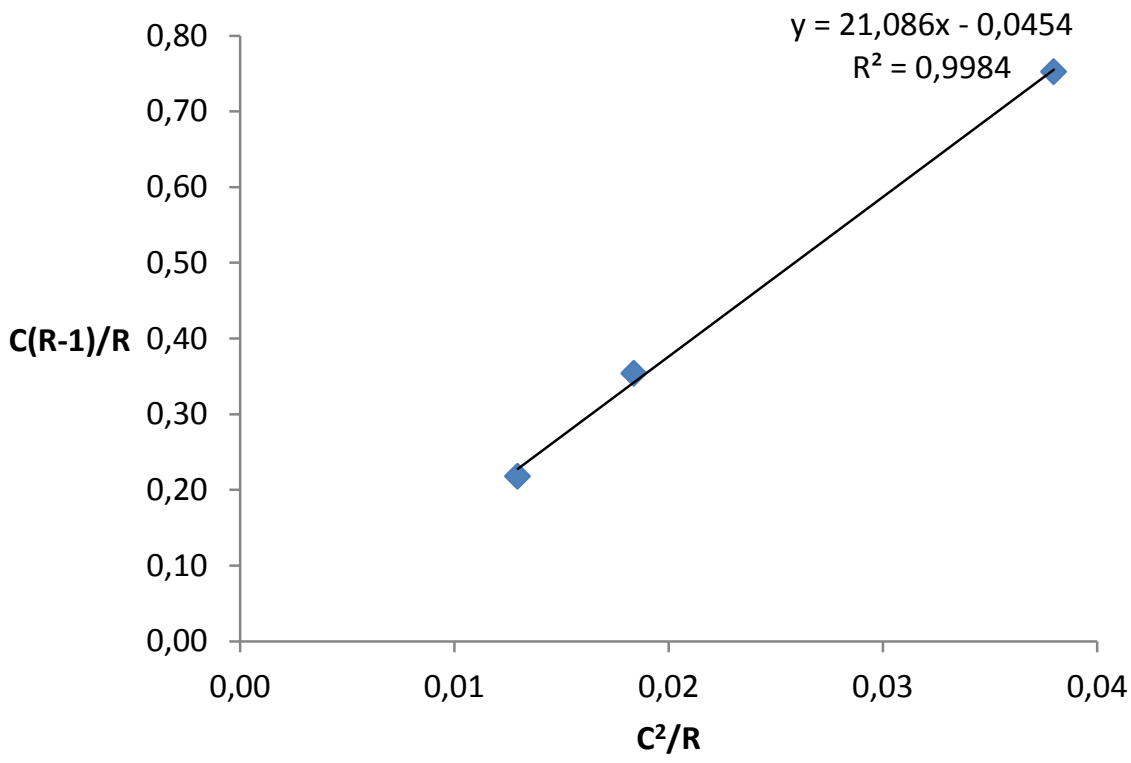

Figure S34. Fineman-Ross plot for ethylene iso-butyl acrylate copolymerizations. 


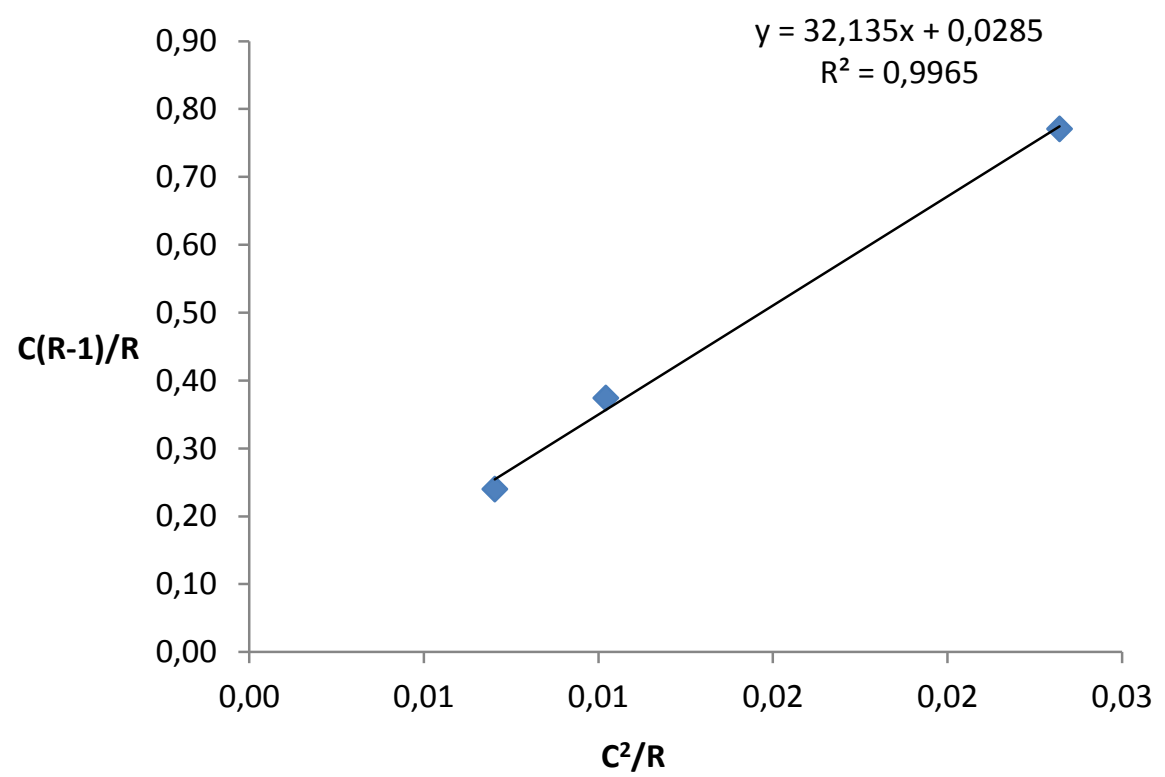

Figure S35. Fineman-Ross plot for ethylene tert-butyl acrylate copolymerizations. 


\section{References}

(1) Guironnet, D.; Roesle, P.; Rünzi, T.; Göttker-Schnetmann, I.; Mecking, S. J. Am.Chem. Soc. 2009, 131, 422-423.

(2) Skupov, K. M.; Marella, P. R.; Simard, M.; Yap, G. P. A.; Allen, N.; Conner, D.; Goodall, B. L.; Claverie, J. P. Macromol. Rapid Commun. 2007, 28, 2033-2038.

(3) Rünzi, T.; Tritschler, U.; Roesle, P.; Göttker-Schnetmann, I.; Möller, H. M.; Caporaso, L.; Poater, A.; Cavallo, L.; Mecking, S. Organometallics 2012, 31, 8388-8406.

(4) Rünzi, T.; Baier, M. C.; Negele, C.; Krumova, M.; Mecking, S. Macromol. Rapid Commun. 2015, 36, 165-173.

(5) Ittel, S. D.; Johnson, L. K.; Brookhart, M. Chem.Rev. 2000, 100, 1169-1204.

(6) Vela, J.; Lief, G. R.; Shen, Z.; Jordan, R. F. Organometallics 2007, 26 (26), 6624-6635.

(7) Kanazawa, M.; Ito, S.; Nozaki, K. Organometallics 2011, 30, 6049-6052.

(8) Azoulay, J. D.; Gao, H.; Koretz, Z. A.; Kehr, G.; Erker, G.; Shimizu, F.; Galland, G. B.; Bazan, G. C. Macromolecules 2012, 45, 4487-4493.

(9) Ullmann's Encyclopedia of Industrial Chemistry, Wiley-VCH Verlag GmbH \& Co. KGaA: Weinheim, 2007.

(10) Boffa, L. S.; Novak, B. M. Chem. Rev. 2000, 100, 1479-1494.

(11) Drent, E.; van Dijk, R.; van Ginkel, R.; van Oort, B.; Pugh, R. I. Chem. Commun. 2002, 744-745.

(12) Rünzi, T.; Mecking, S. Advanced Functional Materials 2014, 24, 387-395.

(13) Rünzi, T. PhD Thesis, Konstanz, 2014.

(14) Rünzi, T.; Fröhlich, D.; Mecking, S. J. Am. Chem. Soc. 2010, 132, 17690-17691. 
(15) Ito, S.; Kanazawa, M.; Munakata, K.; Kuroda, J.-i.; Okumura, Y.; Nozaki, K. J. Am. Chem. Soc. 2011, 133, 1232-1235.

(16) Kakinuki, K.; Fujiki, M.; Nomura, K. Macromolecules 2009, 42, 4585-4595.

(17) Bouilhac, C.; Rünzi, T.; Mecking, S. Macromolecules 2010, 43, 3589-3590.

(18) Friedberger, T.; Wucher, P.; Mecking, S. J. Am. Chem. Soc. 2011, 134, 1010-1018.

(19) Kochi, T.; Noda, S.; Yoshimura, K.; Nozaki, K. J. Am. Chem. Soc. 2007, 129, 89488949.

(20) Luo, S.; Vela, J.; Lief, G. R.; Jordan, R. F. J. Am. Chem. Soc. 2007, 129, 8946-8947.

(21) Ravasio, A.; Boggioni, L.; Tritto, I. Macromolecules 2011, 44, 4180-4186.

(22) Ito, S.; Munakata, K.; Nakamura, A.; Nozaki, K. J. Am. Chem. Soc. 2009, 131, 1460614607.

(23) Fineman, M.; Ross, S.D. J. Polym. Sci. 1950, 259-265. 